ANUARIO DE Estudios MEDIEVALES

46/2, julio-diciembre de 2016, pp. 939-973

ISSN 0066-5061

doi:10.3989/aem.2016.46.2.11

\title{
ORACIONES POR LA SALVACIÓN DEL ALMA. EL OBITUARIO EN PIEDRA DEL MONASTERIO DE SANT PAU DEL CAMP EN BARCELONA
}

\author{
PRAYERS FOR THE SALVATION OF THE SOUL. \\ OBITUARY IN STONE IN SANT PAU DEL \\ CAMP MONASTERY IN BARCELONA
}

\author{
JAVIER DE SANTIAGO FERNÁNDEZ \\ Universidad Complutense de Madrid
}

\begin{abstract}
Resumen: El presente artículo estudia la función pretendida para un grupo de inscripciones conservadas en el monasterio de Sant Pau del Camp, en Barcelona. Se analiza el objetivo con el que las mandaron ejecutar sus autores morales, al tiempo que pretende descubrir quiénes fueron éstos. Se trata de responder a las preguntas de ¿quién? y ¿para qué? Este conjunto de inscripciones resulta singular en el conjunto del panorama epigráfico conocido del Medievo hispano; tales epígrafes no pueden ser asimilados sin más a los llamados epitaphia necrologica, dado que los existentes en Sant Pau del Camp realizan especial incidencia en la fundación de aniversarios que garantizan, $\mathrm{o}$ al menos así lo pretenden, la oración perpetua por el alma del difunto, hecho que no suele ser habitual en otras zonas peninsulares y que ha permitido conceptuar a algunas de ellas como fundationes anniversarii. Sí se localizan inscripciones similares en otros puntos de Cataluña y, especialmente, en la mitad sur de Francia. Se analiza también la relación de estos epígrafes con otros documentos escritos: los obituarios y los testamentos.
\end{abstract}

Palabras clave: epigrafía medieval; fundación de aniversarios; inscripciones necrológicas; monasterio de Sant Pau del Camp.

\begin{abstract}
This paper examines some inscriptions preserved in the monastery of Sant Pau del Camp, in Barcelona, in order to determine their functionality and find out who were their moral authors. We try to answer the questions of who and why. This collection of epigraphs is peculiar in Spanish medieval epigraphy; it cannot be assimilated exactly to epitaphia necrologica, because those in Sant Pau del Camp specially emphasize the foundation of anniversaries, that guarantee perpetual prayer for the deceased's soul. Consequently, we have conceptualized some of these inscriptions as fundationes of anniversary. This tradition is not habitual in other areas of the Iberian Peninsula, except Catalonia. Also, we can find similar inscriptions in the south of France. We also analyze the relationship of these epigraphs with obituaries and testamentary dispositions.
\end{abstract}

Keywords: medieval epigraphy; anniversaries foundation; inscriptions obituary; Sant Pau del Camp monastery. 


\section{SUMARIO}

1. Introducción.- 2. Las inscripciones.- 3. El libro, la inscripción y el documento. Obituarios, epitaphia necrologica y testamentos.- 4. Autoría y función de las inscripciones.- 5. Bibliografía citada

\section{INTRODUCCIÓN}

Al estudiar el conjunto de inscripciones necrológicas, o epitaphia necrologica según las denominan Martín López y García Lobo ${ }^{1}$, conservadas en el claustro del monasterio de San Juan de la Peña, Durán Gudiol utilizó la expresión de necrologium pétreo ${ }^{2}$. Con términos similares se refirió García Lobo a las inscripciones del claustro de Santo Domingo de Silos, obituario en piedra ${ }^{3}$ fue el enunciado que empleó. Ambas son denominaciones de gran acierto, por cuanto califican con precisión el carácter de dichos grupos epigráficos, su función y, especialmente, su vinculación con los libros obituarios, tan comunes en los monasterios. Si tomamos la definición de necrologio y de obituario dada por Herrero Jiménez, en ambos casos, decimos, estamos ante un calendario en el que se inscriben nombres de difuntos por los cuales la comunidad debe hacer una conmemoración en el día del aniversario de su muerte $e^{4}$, observamos que esta idea puede aplicarse a conjuntos epigráficos como los constatados en San Juan de la Peña o Santo Domingo de Silos, pues como en los libros también en ellos encontramos nombres de difuntos, en muchos casos con la correspondiente referencia a las fechas de fallecimiento.

El monasterio benedictino de Sant Pau del Camp conserva un interesante conjunto epigráfico que aparentemente podría adaptarse a la citada denominación, a pesar de que no todas las inscripciones que forman parte de él pueden ser calificadas de epitaphia necrologica ni sus características son exactamente las mismas que las observadas en los lugares antes citados. Se trata de una serie de inscripciones cuyo denominador común es el recuerdo de la muerte, no de la sepultura, de determinados personajes $\mathrm{y}$, muy especialmente, la introducción de fórmulas directamente ligadas a las mandas testamentarias que ordenan la fundación de aniversarios y estipulan, en consecuencia,

\footnotetext{
${ }^{1}$ Martín, García 2009, p. 191. Indican estos autores que estas inscripciones "dan noticia de la muerte de una persona. Se identifican por el verbo obiit y su correspondiente romance falleció", su formulario las distingue de los epitaphia sepulcrales pues, a diferencia de éstos, no indican que el lugar de la inscripción sea el del reposo del difunto.

${ }^{2}$ Durán 1967, p. 65.

${ }^{3}$ García 1990, p. 88.

${ }^{4}$ Herrero 1994, pp. 52-53.
}

ANUARIO de Estudios Medievales, 46/2, julio-diciembre 2016, pp. 939-973

ISSN 0066-5061, doi:10.3989/aem.2016.46.2.11 
determinadas donaciones al monasterio. Esto último no es frecuente en los conjuntos de inscripciones procedentes de otros puntos de la geografía peninsular que denominamos obituarios en piedra; mayor coincidencia hay con inscripciones ubicadas en la catedral de Barcelona y en determinados centros de Girona. Las de Sant Pau del Camp servirán para estudiar las características de estas inscripciones que, de acuerdo a lo que conocemos hasta ahora, parecen vincularse mayoritariamente, en la Península Ibérica, a las tierras catalanas.

Común a todos estos conjuntos, también al que aquí nos ocupa, es la utilización publicitaria de la escritura ${ }^{5}$ para recordar a diferentes personas que o bien eran miembros de la comunidad religiosa o bien fueron benefactores de ella, por lo que se perpetuó su recuerdo mediante epígrafes situados en la mayor parte de las ocasiones en los claustros o en lugares de amplia notoriedad del templo. Pero ¿fue el recuerdo de estas personas el único motivo que impulsó a los que encargaron las inscripciones o existió algún otro? Los diferentes trabajos que han estudiado estos tipos de epígrafes ya han planteado diferentes cuestiones al respecto. En éste efectuaré diversas reflexiones a partir de la información transmitida por los epígrafes de Sant Pau del Camp. Obviamente ello supone contestar a la pregunta ¿para qué se hicieron las inscripciones?; se trata de intentar penetrar en la función realizada por el epígrafe. La comprensión de estos problemas exigirá responder también a cuestiones acerca de quién los realizó y cómo los hizo.

\section{LAS INSCRIPCIONES}

El monasterio de Sant Pau reúne un conjunto de 16 inscripciones, de las cuales cinco se han perdido, si bien conservamos memoria de ellas por haber sido estudiadas por autores anteriores o por copias literarias. Únicamente tendremos en cuenta en este estudio las que forman parte de lo que

\footnotetext{
${ }^{5}$ Partimos de una consideración del epígrafe como un texto escrito que tiene una intención publicitaria, difundir dicho texto al mayor número de personas posible, pretendiendo generalmente también la perdurabilidad, que ese mensaje se perpetúe de generación en generación. Es ésta una visión de la inscripción ampliamente aceptada en la investigación epigráfica, tanto la referente a época antigua como la centrada en el Medievo, desde que Gómez Moreno definiera a la inscripción como "composición literaria para conmemorar un hecho en condiciones monumentales", añadiendo que "publicidad solemnidad y perduración la caracterizan y éstos son los requisitos exigibles para entrar en el noble acervo de la Epigrafía", Gómez-Moreno 1953,p. 93. Desde entonces la valoración de la importancia del elemento publicitario en la investigación epigráfica ha sido creciente y bibliografía que incide en esta idea ha sido profusa, tanto en el ámbito del mundo antiguo como del medieval. Cito a continuación algunas obras significativas a modo de ejemplo: Robert 1961, p. 459; Favreau 1969, 1995a; Petrucci 1986; Susini 1989; Alföldy 1991; García 1991; Donati 2002; Debiais 2009.
} 
podríamos considerar obituario en piedra, pues las restantes corresponden a tipologías epigráficas diferentes por tener un carácter meramente sepulcral, cuatro de ellas, y exhortativo, la restante ${ }^{6}$. Como antes señalé, en el conjunto objeto de estudio no todas caben de manera estricta dentro de la denominación de epitaphia necrologica, es decir el tipo de inscripciones que habitualmente componen los obituarios en piedra, cuya característica primordial es el recuerdo de la muerte de una persona, de ahí que su verbo notificativo sea obiit en la mayor parte de los casos. De acuerdo a sus formulismos, algunas parecen dar más importancia a la fundación de aniversarios, reseñando incluso diferentes donaciones otorgadas al monasterio con tal fin, que al propio acto de la muerte y, de hecho, en éstas el verbo notificativo de la constitución del aniversario es el que va ligado a la intitulatio de la inscripción, quedando la notificación de la muerte vinculada a la data. Son estas últimas las que hemos denominado fundationes anniversarii. A pesar de las diferencias formulares que distinguen ambos tipos de inscripciones, cuestión en la que incidiré más adelante, veo comunidad de intenciones en ambos tipos, e incluso en el mandatum ${ }^{7}$ que se conserva en el monasterio, en el cual subyace una clara intención fúnebre, al ordenar la celebración de misas de difuntos por la salvación del alma de Pedro de Pincerna. La intención final de estas inscripciones será uno de los aspectos que desarrollaré en el presente artículo.

Los epígrafes en cuestión, ordenados cronológicamente, tienen el texto siguiente ${ }^{8}$ :

\section{Mandatum de Pedro Pincerna. Siglo XII. Desaparecida9}

(Crux) $\mathrm{P}(\mathrm{er})$ alodiis, domib(us) atq(u)e a(nni)ver(sar)is que hic / cenobio ego Petrus Pinncerna trado, q(u)idam monach(us $)^{10} /$ augeatur i(n) hi(c) $)^{11}$ cenobio, $q(u) i \mathrm{p}(\mathrm{er}) \mathrm{m}(\mathrm{e})$ et $\mathrm{p}(\mathrm{er}) \operatorname{defu(n)ctis}$ / fidelib(us) in hoc alt(a)ri beati Nicho/lai missas cotidi CCC le-

${ }^{6}$ Se trata del conocido epitaphium sepulcrale del conde Wifredo Borrell, Santiago 2003, p. 333, núm. 54; la hortatio situada en el dintel de la puerta de entrada a la iglesia, ibidem, pp. 338-339, núm. 61; el epitaphium sepulcrale de los fundadores del monasterio, Vigué 1974,p. 202, núm. 3; el de Beltrán de Belloc, ibidem 1974, p. 204, núm. 5; y el de Narcis Desprats, ibidem, pp. 208-209, núm. 10.

${ }^{7}$ Inscripciones que sirven para encargar el cumplimiento de una orden, un acuerdo u otra disposición que obliga moral o jurídicamente al colectivo al que va dirigida, Martín, García 2009, p. 192.

${ }^{8}$ Todas ellas fueron recogidas en Vigué 1974, pp. 197-214; autor que las edita mediante la transcripción, sin resolver las abreviaturas, y la traducción al catalán. He incluido en nota a pie de página las diferencias de lectura observadas.

${ }^{9}$ Vigué 1974, pp. 211-212, núm. 12.

${ }^{10}$ Ibidem transcribe MONNACH(us).

${ }^{11}$ Ibidem transcribe $H$ '. 
bet $^{12}, /$ q(uo)d si aliter actu(m) fuaerit ${ }^{13}$ hospita/lariis ${ }^{14}$ et barch(i) nodensib(us) civib(us)/ licitu(m) erit, q(uo)d traditu(m) est huic / ad aliu(m) religiosu(m) locu(m) transfer/re per LX dies monachis istis prius / i demendare amoditis (crux).

2. Fundatio anniversarii del hermano Berenguer de Solicrup y de su padre Ramón. $1293^{15}$.

F(rate)r B(e)r(en)g(ar)i(us) de Solicrupo,p(r)ior hui(us) / dom(us), co(n)stituit hi(c) an(n)iversariu(m) / et flocos monacoru(m). Q(u)i obiit / anno D(omi)ni M CC XC III, XIII k(a)l(endas) octob(ris). / R(aimundus), pat(er) ei(us) sta(tuit) hi(c) an(n)iversarium. / Obi(i)t VII id(us) ap(r)ilis / an(n)o D(omi)ni M CC LX.

3. Epitaphium necrologicum de Guillermo de Bruguera. 1293. Desaparecida ${ }^{16}$.

(Crux) Anno D(omi)ni M CC XC III obiit G(uillermus) de Brugar/ia, q(u)i duo anniv(er)saria in die obit(us) sui hic constitu/it, $\mathrm{unu}(\mathrm{m})$ videlicet $\mathrm{q}(\mathrm{u})$ od detur in pane pauperib(us) $\mathrm{Ih}(\mathrm{es}) \mathrm{u}(\mathrm{s})^{17} /$ Chr(ist)i, aliud pro pieta(n)cia ${ }^{18} \operatorname{co}(\mathrm{n})$ ventui, $\mathrm{q}(\mathrm{u}) \mathrm{i}$ celebrent / et faciant solle(m)pnit(er) officium mortuoru(m) i(n) il/la die. Que anniv(er)saria assigna(n)tur sup(er) ospicium / R(aimundi) de Colpeyeres et Math(e)i de Collo, Michaelis / de Collo, Bere(n)garii Va(n)relli. Que (m) totu(m) honore $(\mathrm{m}) / \mathrm{ip}(\mathrm{s})$ e emit a Petro de Capellatis et a Bere(n)gario,/ filio suo, $\mathrm{p}($ re $)$ cio triu(m) miliu(m) solidorum (Crux).

4. Fundatio anniversarii de fray Berenguer de Riu. $1300^{19}$.

F(rate)r Bere(n)gari(us) de Ri/vo, p(ri)or h(u)i(us) loci, q(u)i / sta(tuit) hi(c) an(n)iversari/um et obiit IIII k(a)l(endas) / ianuarii anno D(omi)ni MCCC.

5. Fundatio anniversarii de fray Guillermo Despuig. $1300^{20}$.

Frater Guill(ermus) de Podio, monach(us) isti(us) loci, pro / a(n)i(m)a sua instituit q(ui) secuntur: unu(m) anive/rsariu(m) elemosin(ae) IX solidoru(m), picta(n)tia IX / solidoru(m), in co(n)

\footnotetext{
${ }^{12}$ Ibidem transcribe LEBRET.

${ }^{13}$ Ibidem transcribe FVERIT.

${ }^{14}$ Ibidem transcribe HOSPITALARIS

${ }^{15}$ Ibidem, pp. 201-202, núm. 3.

${ }^{16}$ Ibidem, pp. 209-210, núm. 11.

${ }^{17}$ Ibidem transcribe $I K V$.

${ }^{18}$ Ibidem transcribe PIGTACIA.

${ }^{19}$ Ibidem, p. 205, núm. 6.

${ }^{20}$ Ibidem, pp. 206-207, núm. 7.
} 
cepcione $b(e a) t e^{21} M($ arie) lumi(n)aria cera / sex solid(or)u(m), in altari b(ea)te ${ }^{22} \mathrm{M}$ (arie) et in eccl(es)ia ${ }^{23}$ olei $^{24}$ dua $^{25} /$ la(m)peda$\mathrm{ra}^{26}$, unu(m) cereu(m) $\mathrm{p}$ (ro) corpore $\mathrm{Chr}$ (ist)i die cena D(omi)ni./ una candela in natal(e $)^{27} \mathrm{D}(\mathrm{omi})$ ni resurrectio(n)is et ass $/ \mathrm{u}(\mathrm{m})$ ptio(n)is ${ }^{28} \mathrm{~b}\left(\right.$ ea)te $\mathrm{M}($ arie $)$ et celeb(r)acione ${ }^{29}$ triu(m) missaru(m) / qualibet septimana in altari $\mathrm{s}(\mathrm{an}) \mathrm{c}(\mathrm{t}) \mathrm{i}^{30} \mathrm{Iac}(\mathrm{o}) \mathrm{bi}$./ Orate pro eo, qui obiit anno D(omi)ni M CCC.

6. Epitaphium necrologicum de Pedro Colteller, su hijo Pedro y Berengaria. 1304. Desaparecida ${ }^{31}$.

IV idus decembris anno Domini / MCCLXXXIII obiit Petrus Cultellarius,/ qui suum anniversarium hic constituit,/ et anno MCCCIV, XVI kal(endas) augusti,/ Petrus, eius filius, monachus istius / loci, et anno MCCCII, XVIII kal(endas) iulii,/ Berengaria, uxor eius, quo hic unum stabilivit anniversarium.

7. Epitaphium necrologicum de Guillermo de Belloc. $1307^{32}$.

VI n(o)n(a)s madii an(n)o D(omi)ni M CCC VII obiit G(uillelmus) de Pulcro $^{33}$ Loco, qui anniversariu(m) / hic constituit et est cum suis parentibus hic sepultus. Et fue/runt hic tr(a)nslata corpora spectabilium Guibberti Guitardi / et uxoris eius Rotlendis, qui hoc cenobiu(m) fundaverunt et roma/ne $\operatorname{Ec}(\mathrm{c}) 1(\mathrm{es})$ ie obtulerunt, III k(a)l(enda)s may(ii) an(n)o M C XVII.

8. Epitaphium necrologicum de Pedro y María de Gavarret, Castelló de Gavarret y Décima, su mujer. 1315. Desaparecida ${ }^{34}$.

Obierunt Petrus et Maria de Gavarreto, qui unum / anniversarium hic constituerunt. Et obiit / Decima, uxor Castilio de Gavarreto,

\footnotetext{
${ }^{21}$ Ibidem transcribe $B T A$.

${ }^{22}$ Ibidem transcribe $B T A$.

${ }^{23}$ Ibidem transcribe ECCESI.

${ }^{24}$ Ibidem transcribe OFICI.

${ }^{25}$ Ibidem transcribe $D V O$.

${ }^{26}$ Ibidem transcribe LAPADARV.

${ }^{27}$ Ibidem transcribe NATALI.

${ }^{28}$ Ibidem transcribe ASSVPCIOIS.

${ }^{29}$ Ibidem transcribe CELEBATIONE.

${ }^{30}$ Ibidem transcribe $S T I$.

${ }^{31}$ Ibidem, p. 213, núm. 14.

${ }^{32}$ Ibidem, p. 202, núm. 4.

${ }^{33}$ Ibidem transcribe $P V L C H R O$.

${ }^{34}$ Ibidem, pp. 213-214, núm. 15.
} 
que / constituit duo anniversaria, scilicet / unum novem solidorum conventui et aliud / medii morabitini pauperibus. Et obiit / Castilionis de Gavarreto donatus istius / loci, qui duo anniversaria hic instituit, / scilicet unum novem solidorum conventui / et aliud sex solidorum pauperibus, anno / Domini MCCCXV.

9. Fundatio anniversarii del hermano Pedro Fernández. 1317. Desaparecida $^{35}$.

Fr(ater) Petrus Ferdinandi, prior huius loci,/ fecit hoc capitulum, dormitorium et / anniversarium unum pro se, aliud / pro anima patris eius. Qui obiit / anno Domini MCCCXVII kal(endas) februarii.

10. Fundatio anniversarii del hermano Ramón de Olzinelles y epitaphium necrologicum de su padre Ramón. Post. $1336^{36}$.

F(rate)r R(aimundus) d(e) Ulzinell, p(r)ior hui(u)s loci, stabilivit $\mathrm{V}$ ce/reos i(n) hac ecc(lesi)a et II pita(n)cias, I i(n) festo corp/ oris $\mathrm{Ch}($ rist)i, alia $\mathrm{i}(\mathrm{n}) \operatorname{tra}(\mathrm{n})$ situ eximii pat(r)is $\mathrm{n}(\mathrm{ost}) \mathrm{ri} \mathrm{B}(\mathrm{e}) \mathrm{n}(\mathrm{e})$ $\mathrm{d}(\mathrm{i}) \mathrm{c}(\mathrm{t}) \mathrm{i}$, et / t(r)ia a(n)niv(er)saria, duo p(r)iori et co(n)ve(nto) et I paup(er)i/b(us) Ch(rist)i. Et ad faciendu(m) p(re)d(ict)a emit LXIX s(olido)s et / VI de(narios) ce(n)suales et VIII k(a) 1(enda)s madii a(nno) D(omini) M/ CCC XII obiit R(aimundus), pat(er) p(re)dicti p(r)ioris, q(u)i stabi/livit I aniv(er)sariu(m) IX solidor(um) et ordinavit $\mathrm{p}(\mathrm{r})$ ior $\mathrm{p}(\mathrm{re}) / \mathrm{d}(\mathrm{i}) \mathrm{c}(\mathrm{tu}) \mathrm{s}$ aniv(er)sa(rius) $q(u) o d$ em(er)at $p(e r)$ se du(m) erat i(n)firmari(us) / fiat deceto p(er) d(omi)na mate(r) sua.

11. Epitaphium necrologicum de Blanca Desbosc y su hijo Ponce. $1340^{37}$.

A(nno) D(omin)i M CCC XXXX ${ }^{38}$, XV k(a)l(endas) septe(m) bris / obiit d(omi)n(u)s $\mathrm{s}^{39}$ (sic) Blancha de Boscho, cui(us) / fili(us) Ponci(us), rector Ville Rotund(e $)^{40}$, stabilivit hic tria aniv(er)saria, unu $(\mathrm{m}) /$ pro do $(\mathrm{mi})$ na matre et etia $(\mathrm{m})$ patre suo, a/liud pro se et aliud pro $\mathrm{f}(\mathrm{u}) \mathrm{n}(\mathrm{ct}) \mathrm{e}$ et $\mathrm{g}(\mathrm{er}) / \mathrm{mano}$ suo. Q(u)i Ponci(us) ob(iit) id(us) aug(usti) / a(nno) D(omin)i M CCC XXX IIII.

${ }^{35}$ Ibidem, pp. 212-213, núm. 13

${ }^{36}$ Ibidem, pp. 207-208, núm. 8. Doy la data de 1336 de acuerdo a los datos del priorologio establecido por Pladevall, quien fija el priorato de Ramón de Olzinelles entre 1322 y 1336, si bien indica que quizá fue de nuevo prior entre 1338 y 1347, Pladevall 1974, p. 33.

${ }^{37}$ Vigué 1974, p. 208 , núm. 9.

${ }^{38}$ Ibidem transcribe $X X I X$.

${ }^{39}$ Ibidem transcribe DNA.

${ }^{40}$ Ibidem transcribe VILLA ROTVNDA. 
Las inscripciones datadas abarcan un arco cronológico que va desde 1293 hasta 1340. De ellas, dos corresponden al siglo XIII y nueve al XIV. A las anteriores hay que añadir el mandatum alusivo a Pedro de Pincerna, que puede ser atribuido a la segunda mitad del siglo XII, en función del documento de donación de los bienes citados en el epígrafe ${ }^{41}$ y de la propia escritura de éste, una gótica que muestra todavía reminiscencias de la capital románica ${ }^{42}$. Así pues, con excepción del epígrafe alusivo a Pedro de Pincerna el resto se inscribe en un espacio temporal bastante reducido que sirve como elemento unificador del conjunto objeto de interés y muestra la unidad existente entre las inscripciones que lo componen.

Esta cronología está relacionada de manera obvia con la propia historia del monasterio. Después de la restauración de la vida monástica, que tuvo lugar a principios del siglo XII gracias a la dotación efectuada por los esposos Geribert Guitard y Rotlendis, del linaje de Belloc, el monasterio de Sant Pau dependía del de Sant Cugat del Vallès. A pesar de esta subordinación nominal, Sant Pau del Camp actuó con plena autonomía, amparado en el hecho de estar situado bajo la tutela de la Santa Sede, con obligación de pagar un morabetino de censo. Desde los años centrales del siglo XII se acentúa una tendencia iniciada poco antes que supone el incremento de donaciones a favor de Sant $\mathrm{Pau}^{43}$, período inicial representado por el mandatum de Pedro de Pincerna; posteriormente se multiplican aún más las donaciones y el monasterio inicia una etapa de esplendor que culmina en la primera mitad del siglo XIV, cuando la comunidad alcanza los 9 o 10 miembros, el doble de lo que había sido habitual hasta entonces ${ }^{44}$. Esto coincide con la vitalidad, al menos en lo referente a donaciones al monasterio, que refleja la concentración de inscripciones en estos años. Precisamente la segunda mitad del siglo XIV, justamente cuando desaparecen los epígrafes, inicia una etapa de estancamiento y crisis, generalizada para la mayor parte de las casas monásticas catalanas ${ }^{45}$, decadencia de la que no escapó Sant Pau, con un número escaso de monjes ${ }^{46}$. En conclusión, la utilización del hábito epigráfico va a ser consecuencia de la creciente prosperidad del monasterio, que impulsa las donaciones de diversos personajes en favor de la comunidad de Sant Pau.

He realizado un análisis de los elementos externos de las inscripciones con el objeto de poder verificar o no la existencia de un estilo común que

${ }^{41}$ Mutgé 1992-1993, p. 109.

${ }^{42}$ Koch 1996, pp. 172-175.

${ }^{43}$ Mutgé 2002, p. 22.

${ }^{44}$ Pladevall 1974, p. 32.

${ }^{45}$ Ibidem, p. 33.

${ }^{46}$ Mutgé 2008, p. 92.

ANUARIO de Estudios Medievales, 46/2, julio-diciembre 2016, pp. 939-973 ISSN 0066-5061, doi:10.3989/aem.2016.46.2.11 
pudiese llevar a conclusiones acerca de la autoría física de los epígrafes y relacionar ésta con los autores morales. Dicho estudio pasa por el examen de los soportes, la preparación de éstos antes de recibir la escritura, es decir de su impaginatio $^{47}$, y, por supuesto de la escritura. Sin entrar de manera prolija en la descripción de dicho análisis, que considero innecesario pormenorizar, dado que no es el análisis y descripción de los elementos externos el objetivo de este artículo, la principal conclusión que podemos extraer es la inexistencia de un nexo de unión bien definido entre todas las inscripciones objeto de análisis. A pesar de la proximidad cronológica que indica su data no he sido capaz de identificar un estilo común que pudiera mostrar la existencia de un taller epigráfico vinculado al scriptorium que probablemente existió en Sant Pau del Camp.

Sí se puedan discernir lazos comunes entre inscripciones concretas, coincidencias que podrían denotar un mismo rogatario. Se observan esos rasgos similares en las inscripciones de Berenguer de Solicrup y su padre Ramón (núm. 2) y de Berenguer de Riu (núm. 4). En ellas, aparte de la semejanza gráfica, la relación modular en la escritura es casi la misma, muy próxima a 2,6 . Asimismo se observa un enorme parecido en la forma de situar el signo abreviativo de raya sobrepuesta, colocado en todas las ocasiones, en una y otra inscripción, sobre una letra que reduce su tamaño para que dicho signo quede incluido en la caja del renglón. Además, el material es el mismo y la técnica de ejecución de la impaginatio también lo parece. Son inscripciones separadas únicamente por siete años, con lo cual es perfectamente factible que fueran ejecutadas por una misma mano.

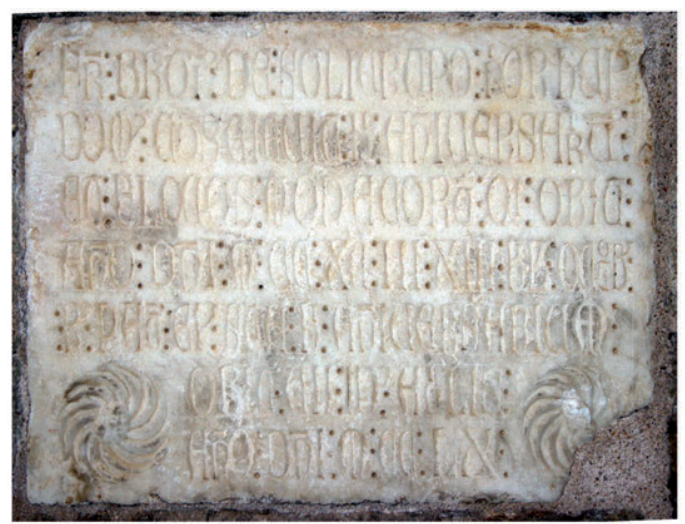

Fig. 1. Fundatio anniversarii del hermano Berenguer de Solicrup y de su padre Ramón.

\footnotetext{
${ }^{47}$ Sobre este proceso técnico en la ejecución de las inscripciones ver, sin ningún ánimo de exhaustividad, Mallon 1957; Susini 1968; Di Stefano 1987; Sartori 1995, 1996; Grasby 1996 , 2002; Martín, García 2012; De Rubeis 2013.
} 
He observado un estilo común, asimismo, entre la inscripción de Guillermo de Belloc (núm. 7) y los epitaphia sepulcralia de Beltrán de Be$1 \operatorname{loc}^{48} \mathrm{y}$ de los fundadores del monasterio ${ }^{49}$ que me parece importante reseñar aunque la segunda y la tercera no forman parte de las inscripciones analizadas en este artículo. Los dedicados a Guillermo de Belloc y a Beltrán de Belloc son los únicos epígrafes del conjunto de Sant Pau del Camp cuyo texto está en el interior de sendas cartelas molduradas, si bien la ejecución de las molduras parece diferente. Cuentan además con una escritura muy característica, también apreciada en el epitafio de los fundadores, por la sensible disminución del ancho de los caracteres en relación con el resto de inscripciones y consiguiente incremento de la relación modular. Obviamente la forma de las letras es también similar. Esto muestra claras relaciones en la ejecución, que se suman a la proximidad de su ubicación, todo lo cual permite hacer alguna consideración de interés. La inscripción dedicada a Beltrán de Belloc tiene data de 1279 , mientras que la de Guillermo corresponde a 1307. Parecen demasiados años para pensar en una misma mano; eso induce a considerar que probablemente la de Beltrán de Belloc no se realizó en la fecha indicada en su data, sino en un momento posterior. Cabe la posibilidad de que esta inscripción y el epitafio de los fundadores fuesen realizados cuando se colocó la de Guillermo de Belloc con objeto de su muerte y la fundación de aniversario, momento en el que, según indica el mismo epígrafe, se trasladaron a este lugar los restos de los fundadores y quizá también los de Beltrán de Belloc. Eso pudo promover la realización de una inscripción alusiva al reposo de los restos de este último; es más, en ella se indica que Beltrán reposa cum genere suo, es decir con los miembros de su linaje, que no pueden ser otros que los fundadores. También sería posible que ambas hubiesen sido ejecutadas algo después. De hecho, el análisis escriturario denota pequeñas diferencias, lo cual pudiera llevar a pensar que la mano no fue la misma, si bien tanto la escritura de la inscripción de Beltrán de Belloc como la del epitafio de los fundadores parece querer imitar a la utilizada en la de Guillermo de Belloc.

48 “(Crux $)$ Hic iacet nobilis Bertrandus de Belloloco cum genere suo, qui multa bona huic monasterio contulerunt; et obiit VII idus apriles an(n)o D(omi)ni M CC LXXIX (crux); editada por Vigué 1974, p. 204, núm. 5.

${ }^{49}$ Esta sencilla inscripción, "(Crux) Hic iacent monasterii fundatores (crux)", Vigué 1974, p. 202, núm. 4, al igual que la dedicada a Beltrán de Belloc, no es objeto de estudio en el presente artículo por no contar con el denominador común que caracteriza al resto, la inclusión de una notificatio referente a la fundación de aniversario o alguna fórmula en la que conste algún tipo de bien donado al monasterio o cláusula testamentaria alusiva con tal fin, y ser simplemente un epitafio sepulcral para recordar el reposo de los difuntos en el lugar indicado. 


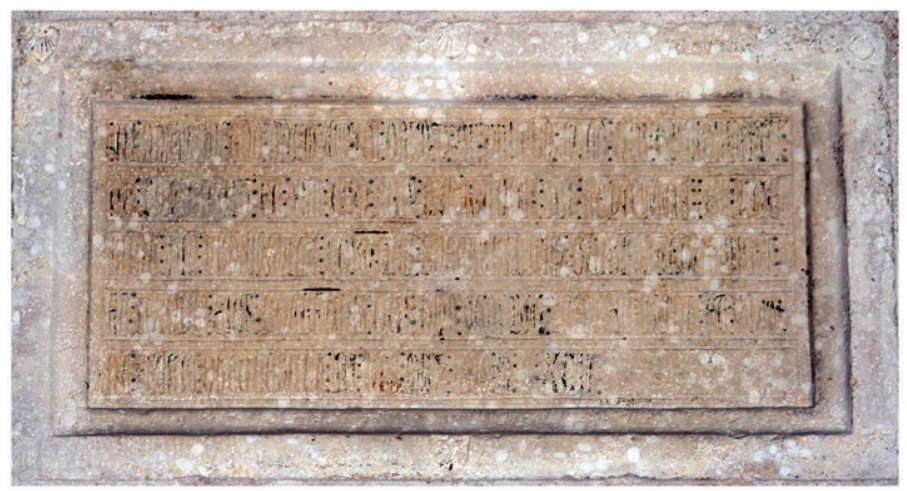

Fig. 2. Epitaphium necrologicum de Guillermo de Belloc.

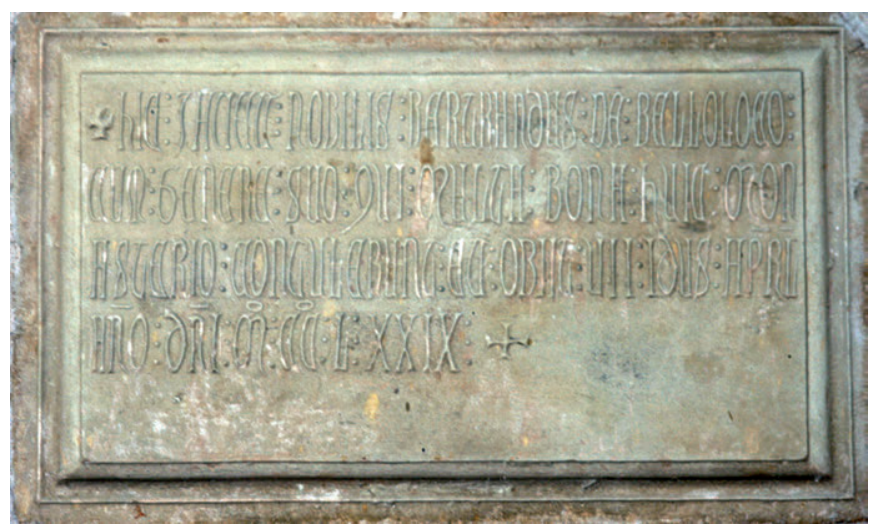

Fig. 3. Epitaphium sepulcrale de Beltrán de Belloc.

Como he señalado repetidamente no todas las inscripciones objeto de estudio pueden ser catalogadas de manera estricta como epitaphia necrologi$\mathrm{ca}$. Es cierto que en todas ellas se incluyen fórmulas referentes a la fundación de aniversarios o la realización de diversas donaciones a favor del monasterio a cambio de obtener ese fin, es decir el bien perpetuo de la oración por la salvación de su alma, pero en algunas la publicitación de tales cláusulas parece el objetivo fundamental, antes incluso que el recuerdo de la muerte del personaje protagonista que es el objetivo esencial de los epitaphia necrologica. En función de tal circunstancia creo que es factible establecer dos tipos de inscripciones. 
El primero es el formado por las que he denominado fundationes anniversarii. Su estructura básica viene dada por la presencia de la intitulatio en primer lugar, seguida de la notificatio del establecimiento del aniversario y a continuación una expositio en la que se indica la muerte del personaje, mediante el verbo obiit, seguido de la data. Lo observamos por ejemplo en la inscripción dedicada a Berenguer de Solicrup y a su padre Ramón (núm. 2). En ella, en la parte dedicada a Berenguer, la intitulatio, se une directamente a la fundación del aniversario, puesto que es el sujeto del verbo constituit, el cual, por tanto, debe ser considerado el verbo notificativo, conformando la siguiente frase, Frater Berengarius de Solicrupo, prior huius domus, constituit hic anniversarium et flocos monacorum, para añadir a continuación, a modo de expositio, qui obiit, situando después la data. Estructura similar a ésta, con algunas variantes, tienen los epígrafes de Berenguer de Riu (núm. 4), Guillermo Despuig ${ }^{50}$ (núm. 5) y Pedro Fernández (núm. 9).

Un segundo grupo está conformado por epitaphia necrologica propiamente dichos, en los que el verbo notificativo es obiit y, por ello, la intención principal de la inscripción parece ser comunicar la noticia de la muerte, añadiendo a continuación la fundación del aniversario y las diversas donaciones. Su formulario tiene cambios en relación con el tipo anterior; comienza por la data, a continuación la intitulatio, seguida del verbo notificativo y de una notificación subsidiaria en la que se informa de la fundación del aniversario y de las donaciones. Lo encontramos en el epígrafe de Guillermo de Bruguera (núm. 3), donde después de la data se escribe que obiit Guillermus de Brugaria, indicando posteriormente qui duo anniversaria in die obitus sui hic constituit, pormenorizando a continuación el destino de la donación y el lugar sobre el que se asentaban las rentas que servirían para el mantenimiento de los aniversarios. Este modelo corresponde también a las inscripciones de Pedro Colteller, su hijo Pedro y Berengaria (núm. 6), la de Guillermo de Belloc ${ }^{51}$ (núm. 7), la de Pedro y María de Gavarret, Castelló de Gavarret y Décima, su mujer, (núm. 8) si bien ésta sitúa la data al final en lugar de al comienzo del texto, y, por último, la de Blanca Desbosc y su hijo Ponce (núm. 11).

El epígrafe de Ramon de Olzinelles y su padre Ramón (núm. 10) está a caballo entre los dos modelos anteriores. En él la parte correspondiente al primero de los personajes citados se acopla al formulario del tipo que denominado fundationes anniversarii y la del segundo tiene la estructura de los epitaphia necrologica.

\footnotetext{
${ }^{50}$ En este se añade una aprecatio, solicitando una oración por el alma del difunto: "orate pro eo".

${ }^{51}$ Esta inscripción informa también en su expositio de la deposición del cuerpo del protagonista y del traslado allí de los restos mortales de los fundadores del monasterio.
} 
A las anteriores hay que añadir la inscripción de Pedro de Pincerna (núm. 1), que comunica la orden de aumentar en un monje la comunidad monástica añadiendo que una de sus dedicaciones ha de ser la celebración de misas diarias por el alma de Pedro Pincerna y por los fieles difuntos en el altar de San Nicolás. Incluye, además, una sanctio, previendo un incumplimiento del mandato, al indicar que si no se cumpliese lo indicado los bienes donados serían traspasados a otro lugar religioso, hecho realmente inusual en el panorama epigráfico conocido. La coincidencia con el resto de inscripciones es la noticia de la donación a cambio de la celebración de los oficios fúnebres, con la introducción de una aparente cláusula testamentaria, como en las anteriores, que parece ser la finalidad principal de la inscripción. Por ello, la he considerado parte del obituario en piedra, a pesar de no ofrecer ninguna notificación necrológica.

Este conjunto de epígrafes tiene algunas variantes en lo referente a sus formulismos, y quizá también en cuanto a su intención y función, respecto a los de otros grandes centros peninsulares a los que puede ser asimilado, como los de San Juan de la Peña, la catedral de Roda de Isabena, el monasterio de Santo Domingo de Silos o el de Santa María de Alcobaça, en Portugal. En las inscripciones de estos lugares el formulario es muy sencillo y repetitivo, buscando fundamentalmente dar noticia de la muerte de una persona y generalmente publicitar también su fecha; es escasa la mención al establecimiento de aniversarios y cuando se efectúa se hace de manera muy sucinta, sin ofrecer apenas más datos. Algunas de las de San Juan de la Peña y Alcobaça incluyen aprecationes expresando fundamentalmente deseos por la salvación del alma del difunto y el descanso del cuerpo, ratificando de esta forma su carácter eminentemente litúrgico. Como acabo de señalar, en algunos de los centros citados se inscribe alguna expresión que se vincula con las cláusulas que caracterizan los epígrafes de Sant Pau. Así en San Juan de la Peña, el epitaphium necrologicum de Guillermo de Arnaldo, que finaliza con la frase qui habet duas processiones ${ }^{52}$ o el del prior García, de quien se dice qui habet tria aniversaria ${ }^{53}$; similar expresión encontramos en la de Domingo de Valle, si bien en este caso los aniversarios fueron $\operatorname{dos}^{54}$. También en la catedral de Roda, en algún caso aislado, se localiza alguna mención a los aniversarios; en concreto ocurre en el epitafio del canónigo Guillermo, en el que se indica habet aniversarium $^{55}$, y en el del prior Berengario de Girueta, qui contulit panis canonicis

${ }^{52}$ Durán 1967, p. 91, núm. 40.

${ }^{53}$ Ibidem, p. 96, núm. 55.

${ }^{54}$ Ibidem, p. 97, núm. 61.

${ }^{55}$ Ibidem, p. 114, núm. 101. 
turniolanensibus pro quo fit aniversarium ter in anno ${ }^{56}$. En Santo Domingo de Silos hay un buen número de epitafios necrológicos que recuerdan el aniversario, generalmente basados en la fórmula anniversarium fiat; son los del presbítero Juan de Espinosa ${ }^{57}$, el del matrimonio formado por León y Dominga $^{58}$, el del monje Miguel $^{59}$, el de Miguel y su mujer Dominga de Espinosa ${ }^{60}$, el de Peregrina ${ }^{61}$, el Juan de Carazo ${ }^{62}$, el de Pascasio, Miguel y Diego de Santa María ${ }^{63}$, el de Vital Palmero y su mujer Dominga ${ }^{64}$. En cualquier caso, suelen ser noticias más breves que las consignadas en Sant Pau del Camp, sin ofrecer detalles más allá del establecimiento del aniversario.

En las inscripciones de Sant Pau del Camp no figura en todas el día exacto de la muerte, a diferencia de lo que sucede en la mayoría de las procedentes de los centros antes citados ${ }^{65}$. Sucede en la inscripción de Guillermo de Bruguera, en la de Guillermo Despuig, en el epitafio de Ramón de Olzinelles ${ }^{66}$, en el de Pedro y María de Gavarret, Castelló de Gavarret y Décima, mujer de éste, y en el mandatum de Pedro de Pincerna, en las que simplemente se indica el año.

Los epígrafes de Sant Pau sí guardan mayor similitud con el panorama que encontramos en otros centros catalanes. Destaca la catedral de Barcelona. En ella se ubicaron en diferentes capillas los epitaphia necrologica de los canónigos Hugo de Cardona $(1333)^{67}$, Guillermo de Banyeres (1384) ${ }^{68}$ y Ramón Amell (1314) ${ }^{69}$, del beneficiado Pedro de Marata $(1346)^{70}$ y de Va-

${ }^{56}$ Ibidem, p. 122, núm. 136.

${ }^{57}$ García 2013, pp. 422-423, núm. 141.

${ }^{58}$ Ibidem, pp. 440-441, núm. 157. En esta inscripción se concreta el momento de celebración del aniversario "anniversarium fiat pro eo in albis".

${ }^{59} \mathrm{Ibidem}$, pp. 470, núm. 185. En este epígrafe se constata la fundación de dos aniversarios al año, "fiat anniversarium bis in anno pro eo".

${ }^{60}$ Ibidem, pp. 474-475, núm. 191. Queda fijado el día de celebración del aniversario, "anniversarium fiat pro eis in albis".

${ }^{61}$ Ibidem, pp. 480-481, núm. 198.

${ }^{62}$ Ibidem, pp. 482-483, núm. 201.

${ }^{63}$ Ibidem, pp. 484, núm. 203.

${ }^{64}$ Ibidem, pp. 494-495, núm. 217.

${ }^{65}$ En muchas de las procedentes de la catedral de Roda falta el año, pero nunca el día del óbito, lo cual es también común a los obituarios. En el monasterio de Santo Domingo de Silos un buen número de estas inscripciones dan noticia de la muerte sin ninguna referencia cronológica, sin citar, por tanto, el año ni el día.

${ }^{66}$ En el de su padre Ramón, en la misma inscripción, sí se indica el día exacto de la muerte.

${ }^{67}$ Mas 1911, p. 62. Procede de la capilla de San Antonio Abad o de Viena.

${ }^{68}$ Ibidem, p. 72. En la capilla de San Vicente, si bien, al parecer, se ubicó allí procedente de la segunda catedral.

${ }^{69}$ Ibidem, p. 82. En la capilla de San Paciano.

${ }^{70}$ Ibidem, p. 105. De la capilla claustral de Santa Lucía, si bien, según Mas, depositada en el archivo. 
lensó $(1401)^{71}$. En el claustro de la seo barcelonesa se situaron inscripciones alusivas a los beneficiados Guillermo de Torrents (1301) ${ }^{72}$ y Bernardo Sampsó $(1341)^{73}$, a los canónigos Ramón de Vilalta (1341) ${ }^{74}$, Galcerán de Barberá $(1319)^{75}$, Berenguer de Noguera $(1323)^{76}$, Pedro de Noguera $(1295)^{77}$, Guillermo Tarafa (1327) ${ }^{78}$ y Guillermo de Bagnariis (1284), al decano Pedro de Olivella ${ }^{79}$ y a Arnaldo Gassol $(1314)^{80}$ y Marcos de Vila (siglo XIV) ${ }^{81}$; a estas inscripciones hay que sumar otras cuyos restos se encuentran en el claustro, pero en las que no ha sido posible leer los nombres y años, debido a su mal estado de conservación. En el claustro de la catedral de Girona se conservan los epitaphia necrologica de Dalmacio de Podialibus ${ }^{82}$, de 1328, y de Arnaldo de Miniana ${ }^{83}$, datada en 1273. En el condado de Peralada también se localiza alguna inscripción de este tipo. Así la alusiva a Guillermo de Avinyó, datada en 1309 y grabada en su urna sepulcral, probablemente procedente del monasterio de Belloc ${ }^{84}$. Del claustro del convento del Carmen proceden la de Guillermo Sort de Vilarnadal, fallecido en $1233^{85}$, y la de Jacobo Gibert, de $1377^{86}$, grabada sobre una urna sepulcral. Del monasterio de San Bartolomé de Belloc es el mandatum de Bernardo de Palacio, datado en $1306^{87}$. En el monasterio de Santa María de Rosas, en su fachada, se ubicó la inscripción de

${ }^{71}$ Ibidem, pp. 166-167. Esta inscripción está en el exterior de la catedral, donde, según Mas, se ubicó a principios del siglo XVI, trasladada desde la capilla de San Antonio Abad.

${ }^{72}$ Ibidem, p. 154.

${ }^{73}$ Ibidem, p. 158-159.

${ }^{74}$ Ibidem, pp. 155-156.

${ }^{75}$ Ibidem, p. 157.

${ }^{76}$ Ibidem, p. 163.

${ }^{77}$ Ibidem, p. 164.

${ }^{78}$ Ibidem, pp. 157-158.

${ }^{79}$ Ibidem, p. 165.

${ }^{80}$ Ibidem, p. 159.

${ }^{81}$ Ibidem, p. 162.

${ }^{82}$ Nonó 2003, pp. 74-75, núm. XXVI. Esta inscripción, además de aludir a la fundación de aniversarios, añade que lo dejó estipulado en su testamento

${ }^{83}$ Ibidem, pp. 102-103, núm. XCV.

${ }^{84}$ Cobos, Tremoleda 2009, pp. 66-67, núm. 5.

${ }^{85}$ Ibidem, pp. 84-85, núm. 14. Esta inscripción resulta curiosa, por cuanto el establecimiento de una lámpara para María fue escrito fuera del campo escriptorio previamente fijado, como si hubiera sido añadido después de acabada la inscripción alusiva al óbito, si bien, al parecer, por la misma mano. La similitud en esto con los obituarios parece clara, especialmente cuando al asiento indicativo del fallecimiento se añadían las fundaciones.

${ }^{86}$ Ibidem, pp. 90-91, núm. 17.

${ }^{87}$ Ibidem, pp. 120-121, núm. 32. La fórmula final de esta inscripción es de gran interés, por cuanto está directamente tomada de la práctica documental: "Actum est kalendis aprilis anno Domini MCCCVI". 
Dalmacio de Garriga, de $1307^{88}$. Grabada en la fachada del monasterio de San Quirzé de Colera estuvo el epígrafe alusivo a fray Berenguer de Vilatenim, muerto en $1320^{89}$. También en la fachada, en este caso en la de la iglesia de San Esteban de Cantallops, se ubica la inscripción de Guillermo Querol ${ }^{90}$, de 1320. Similar posición en la iglesia de San Martín del Far tiene la referente al clérigo y sacristán Pablo, que murió en $1322^{91}$. La fachada de la iglesia de Santa Lucía alberga la de Berenguer de la villa de Pujarnol, del $1341^{92}$. La iglesia de San Martín de Pau conserva en su fachada la inscripción de Berenguera Íbera, muerta en 1329, y su hijo ${ }^{93}$. En un muro de la iglesia de San Juan de Vilatenim se sitúa el epígrafe de Arnaldo de Vilatenim, de $1294^{94}$. Por último, en el condado de Ampurias, en concreto en Sant Cugat de Albons, están los epígrafes dedicados a Arnaldo de Santa Cecilia (1295) ${ }^{95}$ y a Berenguer de Castelló (1308) ${ }^{96}$, en San Pere de Ullastret el de Arnaldo de Terrades (1308) ${ }^{97}$ y en Santa Eulalia de Ultramort el de Arnaldo de Benito (1340) ${ }^{98}$.

A todo lo reseñado hay que añadir que estas inscripciones tienen cierta similitud, si no de contenido y formulismo, sí de intención, con otras procedentes de la catedral de Ebora, correspondientes al último cuarto del siglo $\mathrm{XV}$. En ellas, en el sepulcro del personaje fallecido se indica someramente Aniversairo por $[\text { nombre }]^{99}$.

Lo destacable del conjunto de Sant Pau del Camp es la abundancia y concentración de este tipo de inscripciones, inexistente en el resto de centros analizados, con la excepción de la catedral de Barcelona. Fuera de Barcelona únicamente he podido localizar como mucho uno o dos epígrafes con las características descritas en cada centro, pese a que algunos lugares, como la

\footnotetext{
${ }^{88}$ Ibidem, pp. 144-145, núm. 45. La impaginatio de esta inscripción destaca por estar ubicados sus tres renglones en la parte superior del campo escriptorio, dejando un amplio espacio en blanco, como si estuviera previsto realizar nuevas inscripciones, al igual que sucedía en las páginas de los obituarios. Esto ha sido observado en otros centros como Santo Domingo de Silos, Martín López 2012, p. 238, o San Juan de la Peña.

${ }^{89}$ Cobos, Tremoleda 2009, pp. 178-179, núm. 64.

${ }^{90}$ Ibidem, pp. 182-183, núm. 65.

${ }^{91}$ Ibidem, pp. 184-185, núm. 66.

${ }^{92}$ Ibidem, pp. 188-189, núm. 68. En esta inscripción se muestra de manera explícita su relación con el testamento, "dimisit omnes illos redditus qui sunt comprehensi in instrumentis et testamento et codicilis inde factis" añade al final del texto.

${ }^{93}$ Ibidem, pp. 196-197, núm. 73.

${ }^{94}$ Ibidem, pp. 206-207, núm. 79.

${ }_{95}$ Cobos, Tremoleda, Vega 2010, pp. 152-153, núm. 41.

${ }^{96}$ Ibidem, pp. 156-157, núm. 43.

${ }^{97}$ Ibidem, pp. 198-199, núm. 64. Este epígrafe no indica de manera concreta la constitución de un aniversario, sino la dotación de un presbítero.

${ }^{98}$ Ibidem, pp. 200-201, núm. 65.

${ }^{99}$ Barroca 2000, pp. 284-286.
} 
catedral de Girona, ofrecen un conjunto epigráfico muy notable. De todos modos, e independientemente de otros factores, esta proliferación de inscripciones alusivas a la fundación de aniversarios en un monasterio relativamente pequeño cuadra bien con su carácter benedictino, pues los miembros de la orden de San Benito se especializaron en la plegaria funeraria a partir del siglo $\mathrm{XI}^{100}$.

En lo que sí parecen adquirir mayor particularidad las inscripciones de Sant Pau del Camp es en el formulismo propio de las que he denominado fundationes anniversarii, al menos en el ámbito peninsular. En los lugares examinados no he localizado epígrafe similar, en el que la notificatio se centre en la fundación del aniversario antes que en la defunción. Probablemente esta diferencia no obedezca más que a cuestiones formulares derivadas de diferentes talleres de ejecución. Será necesaria la publicación y análisis de los epígrafes de otros centros religiosos para poder avanzar en el conocimiento de estas peculiaridades.

Este panorama esbozado brevemente permite ver cómo en Cataluña, especialmente en Barcelona, de acuerdo a lo conocido y publicado hasta ahora, afloran, fundamentalmente en el siglo XIV, este tipo de inscripciones de carácter necrológico que inciden en la fundación de aniversarios ${ }^{101}$, a diferencia de lo que sucede en el resto de la Península. Una vez más surge en el panorama epigráfico catalán una conexión e influencia con lo que acaece al norte de los Pirineos, pues en Francia, en la zona sur, han sido atestiguados en una cronología similar ${ }^{102}$ epígrafes en los que, además del óbito, se indican la fundación de aniversarios o diversas donaciones de origen testamentario con tal $\mathrm{fin}^{103}$. Como ejemplo pueden ser citados algunos centros destacados, como la ciudad de Vienne ${ }^{104}$, uno de los lugares donde encontramos gran concentración de este tipo de inscripciones, especialmente en la catedral de Saint Maurice. Otros centros pueden ser el antiguo priorato de Saint Orens, en Auch (Gers) ${ }^{105}$, el claustro de la catedral de Elna, diversos templos en Perpignan $^{106}$, Narbona $^{107}$, etc.

\footnotetext{
${ }^{100}$ Treffort 2010, p. 170.

${ }^{101}$ Sí se conoce y es relativamente común la introducción de cláusulas de fundación de aniversarios en los epitaphia sepulcralia.

${ }^{102}$ Los primeros ejemplos parecen ser de mediados del siglo XII.

${ }^{103}$ Treffort 2010, pp. 171-173.

${ }^{104}$ Favreau, Michaud, Mora 1990.

${ }^{105}$ Favreau, Leplan, Michaud 1981.

${ }^{106}$ Favreau, Michaud, Mora 1986.

${ }^{107}$ Favreau, Michaud, Mora 1988; Favreau, Michaud, Leplan 1982, núms. 64-65, 80.
} 


\section{EL LIBRO, LA INSCRIPCIÓN Y EL DOCUMENTO. OBITUARIOS, EPITAPHIA NECROLOGICA Y TESTAMENTOS}

Son numerosas las ocasiones en las que García Lobo se ha referido a la analogía existente entre las ciencias de la escritura, analogía que fundamenta en la existente entre los propios objetos escritos en $\mathbf{s i}^{108}$. Tal realidad es especialmente perceptible en el grupo de inscripciones analizadas en este artículo. Como se ha afirmado en repetidas ocasiones, y señalé al principio de este trabajo, las inscripciones necrológicas tienen una profunda relación con los libros llamados obituarios, vínculo derivado de la comunidad de su contenido y del hecho de que el texto de las inscripciones parece directamente tomado de los obituarios de los monasterios, en los que se recogía la relación de personas por las que los monjes tenían la obligación de orar. Eso condujo a Durán Gudiol a identificar estas inscripciones con una parte del necrologio grabada en sillares de los respectivos claustros. Tan profundas son a veces las similitudes en el formulario y en el tenor textual del libro obituario y de los epitaphia necrologica que estos epígrafes han llegado a ser considerados por el citado autor copias en piedra de un necrologium u obituario ${ }^{109}$, pues en buena medida trasladan la información del obituario a los muros pétreos de los claustros monásticos o catedralicios.

Tanto inscripciones como libros están directamente relacionados con la oración en pro de la salvación del alma del difunto. El cristiano, a través de su oración, podrá interceder por sus muertos, interfiriendo en el destino que éstos se hubieran forjado a través de la vida terrena. Todo cristiano siente la necesidad de la oración para obtener la salvación, para lograr el perdón de los pecados mundanos, y sabe que esa oración es necesaria aún después de la muerte. Por ello, los muertos permanecen y están presentes en la oración de los vivos, en la oración de la Iglesia. Existe una creencia en la eficacia de la oración para conseguir la purificación de los pecados de los difuntos y obtener, de este modo, la salvación ${ }^{110}$. El hombre medieval tratará de poner a lo largo de su vida todos los medios necesarios para obtener la salvación. Relacionado con esto y con la eficacia al respecto de la oración, la fundación de aniversarios juega un importante papel; la oración era imprescindible para la salvación del alma, pero será la fundación de aniversarios lo que garantice su continuidad, al proporcionar una renta que permite obtener el dinero necesario para mantenerla en el tiempo. Pretendían los fieles que su generosidad, ofre-

${ }^{108}$ García 2012,p. 11.

${ }^{109}$ Durán 1967, p. 47.

${ }^{110}$ Huyghebaert 1972, p. 17. 
ciendo donaciones terrenales que en nada servirían al difunto una vez muerto, se compensase con las oraciones y sufragios que por ellos ofrecerían los religiosos. Como consecuencia de esto se crearán los obituarios, documento necrológico donde se registran los difuntos de una comunidad, así como los aniversarios que se fundan para beneficiarse eternamente de la oración de los vivos ${ }^{111}$. La organización de estos libros ${ }^{112}$ se realiza en forma de calendario, disponiendo los nombres según el día de su fallecimiento o de acuerdo al día escogido en vida por el propio difunto para la celebración del aniversario, sin que necesariamente tuviera que coincidir con la fecha de la muerte.

Los epitaphia necrologica guardan claros vínculos con el obituario. La coincidencia cronológica es clara; va a ser a partir del siglo XII cuando los simples necrologios empiecen a introducir alusiones a la fundación de aniversarios y se transformen en obituarios. Precisamente a finales del siglo XII y, especialmente, en el XIII se empiezan a ver este tipo de epígrafes en los grandes centros religiosos. Es una época que además coincide con la intensificación de la producción epigráfica, como se observa al analizar los grupos epigráficos peninsulares publicados, los cuales incrementan notoriamente el número de inscripciones a partir de la décimotercera centuria. Los siglos bajomedievales experimentan una creciente expansión del hábito de escribir, que lógicamente afecta al llamado hábito epigráfico y provoca que su empleo se extienda a grupos sociales que hasta entonces habían permanecido ajenos a él. Tal generalización en la costumbre de realizar epígrafes probablemente influyó, o al menos pudo hacerlo, en que el recuerdo de la muerte y de la oración necesaria para la salvación del alma pasara del libro a la inscripción. Al igual que los obituarios, los epitaphia necrologica son resultado de la creencia en la eficacia de la oración por los muertos. También en ellos, como en aquellos, serán los benefactores del monasterio o institución religiosa que los alberga, que instituyen una fundación para la oración en el aniversario de su muerte, los protagonistas.

Como repetidamente he indicado no todas las inscripciones objeto de estudio pueden ser consideradas epitaphia necrologica, sin embargo no por ello su nexo de unión con los obituarios es menos intenso. Precisamente una característica de las inscripciones de Sant Pau del Camp es difundir y recordar prácticamente todas ellas la fundación de aniversarios. En varias, además, se indica la renta sobre la que se asienta la fundación y las obras de misericordia que en ocasiones acompañan a los aniversarios. Así en la de Guillermo de Bruguera (núm. 3) se señala que fundó dos aniversarios,

\footnotetext{
${ }^{111}$ Serna 2008, p. 30.

${ }^{112}$ Las características de los obituarios han sido minuciosamente estudiadas en Herrero 1994, 2011; Serna 2008, pp. 199-220. Estas publicaciones han sido las que he utilizado preferentemente en esta pequeña aproximación a los obituarios.
} 
unum videlicet quod detur in pane pauperibus Ihesus Christi, aliud pro pietancia conventui y que assignantur super ospicium Raimundi de Colpeyeres et Mathei de Collo, Michaelis de Collo, Berengarii Vanrelli.

La de Guillermo Despuig (núm. 5) estipula que el aniversario constaba de

elemosinae IX solidorum, pictantia IX solidorum, in concepcione beate Marie luminaria cera sex solidorum, in altari beate Marie et in ecclesia olei dua lampedara, unum cereum pro corpore Christi die cena Domini, una candela in natale Domini resurrectionis et assumptionis beate Marie et celebracione trium misarum qualibet septimana in altari sancti Iacobi.

La de Ramón de Olzinelles (núm. 10) dice que

stabilivit $\mathrm{V}$ cereos in hac ecclesia et II pitancias, I in festo corporis Christi, alia in transitu eximii patris nostri Benedicti, et tria anniversaria, duo priori et convento et I pauperibus Christi y que para conseguirlo emit LXIX solidos et VI denarios censuales, sin dar más datos.

La misma inscripción también contiene la fundación de Ramón, padre del anterior, quien stabilivit I aniversarium IX solidorum. En la de Pedro y María de Gavarret, Castelló de Gavarret y Décima (núm. 8) se reseña como la última

constituit duo anniversaria, scilicet unum novem solidorum conventui et aliud medii morabitini pauperibus y su marido, Castelló, duo anniversaria hic instituit, scilicet unum novem solidorum conventui et aliud sex solidorum pauperibus.

Por último, el mandatum de Pedro de Pincerna (núm. 1) estipula que

Per alodiis, domibus atque anniversaris que hic cenobio ego Petrus Pinncerna trado, quidam monachus augeatur in hic cenobio, qui per me et per defuncti fidelibus in hoc altari beati Nicholai missas cotidi CCC lebet.

Ambos soportes escritos, libro y epígrafe, guardan una evidente conexión con los testamentos. En el siglo XII se reanuda la práctica testamentaria gracias al redescubrimiento del Derecho romano y se desarrolla la idea del Purgatorio reforzando la creencia en la eficacia de la oración para disminuir la estancia en él. Esto conllevará la inclusión en los testamentos de cláusulas 
en las que se estipulan donaciones pías a cambio de la garantizar el rezo por la salvación del alma del difunto ${ }^{113}$, coincidiendo con un momento en el que se generaliza la fundación de aniversarios. Los libros necrológicos tomarán estas cláusulas de los testamentos y las incluirán en sus noticias, añadiéndolas a la de la muerte del personaje. Son noticias de tipo administrativo que, sin duda, habían de facilitar la gestión de aniversarios y fundaciones ${ }^{114}$. A través de esta realidad inscripciones como las aquí estudiadas se relacionan, no sólo con el obituario, sino también con el testamento, circunstancia que no se aprecia en la mayor parte de las inscripciones necrológicas procedentes de otros lugares de la Península. Esta introducción de cláusulas de fundación de aniversarios permite afirmar que en las inscripciones de Sant Pau del Camp la relación con el obituario es más exacta que en aquellas que simplemente dan noticia del óbito y de su fecha y en algún caso de la fundación de aniversario, pero de manera muy escueta, características básicas de los obituarios en piedra hasta ahora estudiados, por cuanto también el libro obituario refleja estas cláusulas de origen testamentario.

Por otro lado, es algo conocido que, especialmente a partir del siglo XIII, comienzan a introducirse de manera frecuente en las inscripciones mandas testamentarias que suponen legados de ciertos bienes a determinados centros religiosos, con la condición de celebrar por su alma sufragios anuales. En la Península esto suele ser habitual en los epitaphia sepulcralia, no en los necrologica; las mandas testamentarias no suelen figurar en los denominados obituarios en piedra de nuestro ámbito geográfico, realidad que, sin duda, otorga singularidad a las inscripciones de Barcelona, y especialmente a las de Sant Pau del Camp, si bien este hecho, como antes cité, también se ha observado en otros lugares de Cataluña, aunque no en el número y profusión con los que lo hemos percibido en la ciudad condal.

Aunque las cláusulas testamentarias acercan las inscripciones de Sant Pau del Camp al obituario, la forma de la disposición de las noticias necrológicas las alejan de él y de alguno de los otros obituarios en piedra estudiados. Como ya he dicho en repetidas ocasiones, los obituarios se organizan de acuerdo al calendario y en cada página correspondiente a un día se asientan las noticias de los fallecidos en tal fecha. Siguiendo esta organización, el obituario en piedra de, por ejemplo, Silos es posible que estuviese basado en la traslación a cada una de las inscripciones de las noticias necrológicas de un día concreto y es de suponer que las anotaciones múltiples en una misma inscripción correspondan al mismo día o al

${ }^{113}$ Ariès 1975 , pp. 188 ss.

${ }^{114}$ Fábrega 1988, pp. 196-197. 
mismo mes, aunque la ausencia de data completa en los textos epigráficos impida aclarar tal punto ${ }^{115}$. Martín López incide en este aspecto y atribuye a esta realidad el hecho de que muchas inscripciones de Silos parezcan incompletas, al quedar una o varias líneas, concebidas inicialmente en la impaginatio, sin escribir; lo relaciona esta autora con la concepción de la inscripción como si fuera el folio del obituario y con la previsión de futuros asentamientos correspondientes a ese mismo día ${ }^{116}$; en Silos tenemos la impresión de estar ante un códice cuyos folios han sido individualizados $y$ adheridos a la pared ${ }^{117}$. En Sant Pau del Camp esto no ocurre. Es cierto que en diversas inscripciones se alude a varias personas, pero en todos los casos la relación no es cronológica, sino familiar, es decir son miembros de una misma familia, generalmente padres e hijos; este es el nexo de unión, no que falleciesen el mismo día.

Si comparamos los datos anteriores con las inscripciones de San Juan de la Peña, observamos similitudes con lo observado en Sant Pau del Camp. En el cenobio oscense existen varios epígrafes en los que efectivamente se observa la presencia de más de un asiento necrológico, incluso en algún caso se puede apreciar que fueron trazados por manos distintas y en otros se advierte espacio libre que permitiría la entrada de nuevos difuntos, lo cual podría asemejarse con lo afirmado para Silos y, de hecho, las similitudes formales son notorias. Sin embargo la sorpresa salta cuando al analizar las fechas se ve que no tienen ninguna coincidencia, exactamente igual a lo que sucede en Sant Pau, sin que podamos saber cuál fue la relación que guió la ejecución de más de un epitaphium necrologicum en un único soporte. Podemos citar diversos casos, pero basta como ejemplo la inscripción que reúne los epitahia de Martín ${ }^{118}$, fallecido el 20 de agosto de 1202, y del prior Egidio ${ }^{119}$, que murió el 6 de abril de 1268; la escritura denota que la mano que trazó ambos asientos es diferente. Esto es lo general entre los epitafios que comparten soporte en San Juan de la Peña. La inexistencia de coincidencia de fechas en los asientos necrológicos de una misma inscripción es también observada por Treffort para el ámbito francés; incide esta autora en que la coincidencia suele estar en que los difuntos son miembros de una misma familia, como en Sant Pau del Camp, interpretándolo como un elemento que demuestra la consciencia de pertenencia al grupo familiar ${ }^{120}$.

\footnotetext{
${ }^{115}$ Martín 2012,p. 237.

${ }^{116}$ Ibidem, p. 238.

${ }^{117}$ García, Martín 1996, p. 144.

${ }^{118}$ Durán 1967, p. 86, núm. 23.

${ }^{119}$ Ibidem, p. 89, núm. 33.

${ }^{120}$ Treffort 2008, p. 127.
} 
En cualquier caso, creo que con todo lo expuesto queda mostrada de manera fehaciente la relación entre el testamento, el obituario y la inscripción. Como indicó Herrero Jiménez, se trata de tres documentos, epigráfico uno, diplomático otro y librario el tercero, que se complementan y se explican ${ }^{121}$.

\section{AUTORÍA Y FUNCIÓN DE LAS INSCRIPCIONES}

La finalidad principal de las inscripciones objeto de estudio, como la de todo epígrafe necrológico, es el recuerdo de los personajes finados mencionados en ellas con la intención de orar por ellos. No hemos de olvidar la función que toda inscripción tiene, también presente en éstas, el mantenimiento de la memoria, en este caso de personalidades importantes para la comunidad monástica, por cuanto eran sus principales benefactores. La misma ubicación en el claustro asegura tal finalidad. El espacio claustral constituye la imagen simbólica, material e inmutable de la cohesión de la comunidad. A través de las inscripciones los personajes en ellas citados se aseguran formar parte de la vida de la comunidad después de su muerte, al hallarse en el corazón del monasterio ${ }^{122}$. Debe tenerse en cuenta que el claustro comunicaba las dependencia conventuales con la iglesia y era lugar de paso obligado para la comunidad monástica. Todas las inscripciones parecen buscar las pandas más transitadas en la vida cotidiana de la comunidad, al estar en los lados del claustro que servían de comunicación más corta entre la residencia de los monjes y el templo, de ahí que sean varias las que se encuentran en las proximidades de la puerta que une el claustro con la iglesia. Aparentemente éste es el único criterio que guía la ubicación de las inscripciones, más allá de que aquellas que se asocian a sepulturas tienen una localización determinada por ésta, probablemente resultado de los deseos del difunto expresados en disposición documental ${ }^{123}$. Parece evidente, por tanto, la intención de asegurar su lectura y el recuerdo permanente por parte de la comunidad y, con ello, su existencia perpetua en el seno de ella.

Sólo tres inscripciones escapan a la ubicación claustral. Una es el mandatum de Pedro de Pincerna (núm. 1), situada en el muro de una de las capillas de la iglesia, en el lugar donde se debían celebrar misas diarias por su alma y por la de los fieles difuntos ${ }^{124}$; qué mejor lugar para recordar la obli-

\footnotetext{
${ }^{121}$ Herrero 2011, p. 214.

${ }^{122}$ Debiais 2006, p. 381.

${ }^{123}$ Orlandis 1976, pp. 267-268.

${ }^{124}$ La localización de esta inscripción únicamente puede ser establecida por referencias anteriores, dado que es una pieza desaparecida. Al parecer, estuvo encastrada en un muro de la 
gación asumida por la comunidad de Sant Pau que aquel donde debía tener lugar la liturgia de difuntos estipulada en el mandatum. La otra es la dedicada a Pedro Fernández, ubicada según Pujades en la sala capitular, por tanto en el centro de la administración de la institución monástica y, además, lugar donde podía tener lugar la lectura del obituario ${ }^{125}$. Parece lógica esta ubicación, por cuanto en la misma inscripción se reconoce al personaje como artífice del capítulo; por tanto, es un lugar ideal para guardar su recuerdo, a lo cual se une que fue allí sepultado, según noticia que ofrece Pujades, quien indica que el sepulcro del personaje estaba dentro de la estancia del cabildo (...) en el suelo, con una inscripción alusiva ${ }^{26}$. La tercera es la de Pedro y María de Gavarret, Castelló de Gavarret y su mujer Décima, que al parecer estaba en el interior de la iglesia, junto a la puerta del crucero $^{127}$.

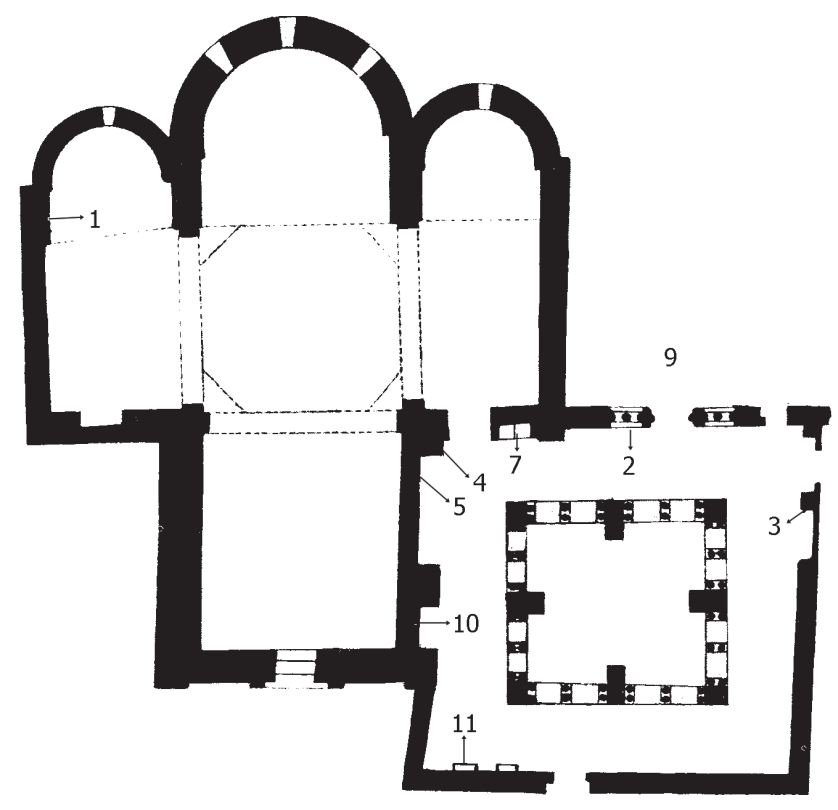

Fig. 4. Plano del claustro de Sant Pau del Camp con la ubicación de las inscripciones.

capilla de San Galdric, junto al altar de San Nicolás y San Benito, Vigué 1974, pp. 211-212; Pujades 1830, p. 43.

${ }^{125}$ Herrero 2011, p. 206.

${ }^{126}$ Pujades 1830, p. 42.

${ }^{127}$ Vigué 1974, p. 204. 
Para los benedictinos la liturgia de difuntos tenía notable importancia y así queda recogido en la Regla. Las oraciones de los monjes pedían por el alma de los abades, monjes, deudos y benefactores. Con ello, a la de recuerdo perpetuo se une en estas inscripciones una finalidad que podríamos denominar litúrgica, la oración por los difuntos, función hace ya tiempo resaltada para los obituarios en piedra de otros monasterios ${ }^{128}$. Aun reconociendo esta intención para las inscripciones de Sant Pau del Camp, no estoy en condiciones de afirmar la existencia de una procesión en la que se oraba por los difuntos a lo largo del claustro, según se ha hecho para Silos, en la cual las inscripciones sustituían al libro, pues hubiera sido demasiado oneroso disponer de un obituario para cada miembro de la comunidad ${ }^{129}$, aunque tampoco es posible rechazar esta idea. También en Francia se ha testimoniado la existencia de procesiones litúrgicas donde las inscripciones funerarias de los personajes importantes para la comunidad religiosa jugaron un papel importante; de esta manera se estableció una ceremonia que, por la publicidad garantizada por las inscripciones, aseguró su permanencia ${ }^{130}$. La antes citada inexistencia de coincidencia de fecha de la muerte entre las personas citadas en una misma inscripción hace pensar que, de existir, dicha procesión no seguiría el orden del calendario, propio de los obituarios. A esto hay que añadir que, como ya indiqué en el apartado descriptivo de las inscripciones, en varias de ellas no se da el día exacto del óbito. En la inscripción de Guillermo de Bruguera (núm. 3), además, se señala qui duo anniversaria in die obitus sui hic constituit (...), qui celebrent et faciant sollempniter officium mortuorum in illa die, es decir se estipula la celebración del oficio fúnebre el día del aniversario, sin indicar cuándo es éste, dándolo por sabido. Obviamente el conocimiento y recuerdo de la fecha exacta sólo era posible merced al libro obituario; por tanto, estas inscripciones carentes de data implican el uso necesario de dicho libro, que sería el instrumento de la liturgia, pero al mismo tiempo permiten deducir la ausencia de una intencionalidad explícita de convertirse en elemento sustitutivo de él. De todos modos, insisto en que esto no implica que no cumpliesen una finalidad de petición de plegarias por el alma del difunto; de hecho una de ellas, la de Guillermo Despuig (núm. 5), concluye con una apprecatio genérica, orate pro eo, fórmula epigráfica conocida desde el siglo IX y de notable frecuencia ${ }^{131}$.

Junto a la intención de recuerdo y de petición de plegaria, subyacen otras no menos importantes. La repetida mención a la fundación de aniver-

${ }^{128}$ Garcia, Martín 1996, pp. 143-144; Martín 2003,p. 481.

${ }^{129}$ Garcia, Martín 1996, pp. 143; Martín 2003, p. 481.

${ }^{130}$ Treffort 2010, p. 173.

${ }^{131}$ Favreau 1995a, p. 162.

ANUARIO DE Estudios MEdiEvales, 46/2, julio-diciembre 2016, pp. 939-973 ISSN 0066-5061, doi:10.3989/aem.2016.46.2.11 
sarios y a donaciones, ha de ser relacionada con el deseo de los difuntos de obtener la salvación eterna mediante el otorgamiento de sus bienes a iglesias o monasterios, deseo que en este caso concreto se refuerza con la oración y misas dispuestas, a cambio de las donaciones, por el alma de los difuntos. Los donatarios obtenían, de este modo, un beneficio espiritual a cambio del terrenal que adquirían las instituciones religiosas y que alimentaban así el incremento de sus dominios territoriales y bienes. Huyghebaert incidió en la función administrativa que tenían los obituarios, recordando a los miembros de una comunidad los servicios de aniversarios fundados por algunos difuntos y las obras de misericordia que acompañaban a dichas fundaciones, indicando en ocasiones de manera concreta cuáles eran las rentas afectadas por los óbitos ${ }^{132}$. Es fácil percibir la relación con las inscripciones de Sant Pau. Sin embargo, la analogía no es, a mi juicio, suficiente para trasladar la función administrativa del obituario a la inscripción. No puede ser el simple recuerdo de la celebración y tener constancia en algunos casos de las rentas de los aniversarios la única intención para trasladar el asiento del libro a la piedra. Para justificar la inclusión en los epitaphia sepulcralia de mandas testamentarias ha sido aducido el deseo de evitar incumplimientos de lo estipulado en los testamentos por parte de los albaceas testamentarios, práctica al parecer bastante común, y de hecho castigada por vía normativa. La publicitación de estas cláusulas prevendría tales desmanes ${ }^{133}$. Los epígrafes del mundo medieval pueden ser, por tanto, entendidos como una manera de afirmar y perpetuar derechos. Trasladando estas ideas a la realidad de las inscripciones de Sant Pau del Camp probablemente podamos entrever una intención de asegurar el cumplimiento de las cláusulas testamentarias más allá del paso del tiempo. Se incluyen en la inscripción con la intención de hacerlas públicas de manera permanente y evitar que la comunidad monástica incumpla lo dispuesto en el testamento o decaiga en el ejercicio de la oración con el correr de los años. En previsión de ello, se da publicidad al encargo. Se pretendería de esta manera reafirmar y legitimar, de cara a las generaciones futuras, el derecho de los difuntos a la celebración litúrgica del aniversario. De hecho, en uno de ellos, el mandatum de Pedro de Pincerna (núm. 1), se explicita la sanción en caso de incumplimiento, seguramente recogiendo lo dispuesto en el testamento. Por tanto, parafraseando a Robert Favreau ${ }^{134}$, el documento, en este caso el testamento, establece los derechos, los aniversarios, y la inscripción los anuncia y los da a conocer a todos, presentes y futuros. Pero no hemos de valorar única-

\footnotetext{
${ }^{132}$ Citado por Herrero 1994, p. 54.

${ }^{133}$ Martín 2002, pp. 370-371; 2010, pp. 112-115; Rodríguez 2009, p. 311.

${ }^{134}$ Favreau 1995a, p. 173.
} 
mente esta funcionalidad en relación con los coetáneos e inmediatos sucesores de los comanditarios de la inscripción. No ha de ser olvidado el carácter de perdurabilidad que comúnmente se asocia, ahora y en el Medievo, al mensaje epigráfico. Refuerza la inscripción lo contenido en los testamentos y obituarios y al mismo tiempo garantiza su permanencia, pues frente a la eventual destrucción o ignorancia del documento o del libro, el epígrafe asegura la transmisión del mensaje a tiempos futuros; evita el posible olvido de lo contenido en el testamento y en el obituario y lo perpetúa por generaciones.

En reciprocidad también es posible pensar que, asimismo, la comunidad monástica pretendiese garantizar el cumplimiento de lo estipulado en el testamento. El hacerlo público serviría para conseguir que los testamentarios entregaran, y los herederos en ningún momento reclamaran, los bienes sobre los que se asentaba la fundación. Evidentemente esto parece plausible en aquellas inscripciones que pormenorizan lo donado, pero $¿ y$ en aquellas en las que tan sólo se cita la fundación del aniversario, sin dar más especificaciones? Obviamente la vaguedad al respecto de estas últimas impide ver en ellas esta función al menos sin remitirnos al testamento o, incluso, al obituario, donde probablemente sí quedaran reflejadas las rentas de las que se nutría el aniversario.

Por último, no hay que olvidar el valor ejemplarizante que puede asumir la inscripción. En este caso, la publicidad rendiría beneficio a la comunidad monástica. A través de los epígrafes los fieles son informados de la fundación de aniversarios de manera que se convierten en ejemplo y en un estímulo para ser también ellos fundadores de aniversarios y, con ello, donatarios del monasterio. Por otro lado, no debemos olvidar que, como ha afirmado Treffort, la fusión entre la memoria de los difuntos y las piedras del edificio venía a reforzar la comunidad eclesial. A través de las inscripciones se mostraba de manera evidente y pública que los fieles participaban en la construcción de una Ecclesia, tanto de forma material como espiritual. Al mismo tiempo, al formar las inscripciones parte del paisaje habitual que contemplaba diariamente la comunidad monástica, podrían contribuir a reforzar el sentimiento de identidad comunitaria ${ }^{135}$.

En conjunto, este tipo de inscripciones avala la trascendencia dada en el mundo medieval a la fundación de aniversarios. Sólo eso puede explicar su traslado del documento y el libro al epígrafe. Como bien afirmó Robert Favreau son los documentos más importantes, en este caso determinadas cláusulas testamentarias, los que son confiados al lapicida que ejecuta las inscrip-

${ }^{135}$ Treffort 2008, pp. 124-125 y 128.

ANUARIO DE Estudios MEdievales, 46/2, julio-diciembre 2016, pp. 939-973 ISSN 0066-5061, doi:10.3989/aem.2016.46.2.11 
ciones $^{136}$. De no ser así, ¿por qué alguien se iba a tomar la molestia y a asumir el costo económico que suponía hacer una inscripción más prolija? Tal hecho tiene que estar fundado en una poderosa razón y esa no puede ser otra que la importancia que se daba a la fundación y publicitación de aniversarios, tanto por parte del difunto y su familia como por la de la comunidad monástica en cuyo seno se albergaba la inscripción.

Obviamente la intención última de las inscripciones está muy relacionada con su autoría moral, es decir con aquellas personas, o grupo de personas, que ordenaron su ejecución. Cuando realizaron el encargo lo hicieron persiguiendo uno o varios objetivos. Resulta por ello importante intentar saber quién o quiénes estuvieron detrás de la elaboración de los epígrafes. Obviamente una primera aproximación a esta cuestión requiere revisar quiénes son los personajes recordados en las inscripciones. La fundación de un aniversario es resultado de un acuerdo entre el benefactor-fundador y la comunidad monástica, aunque en ocasiones ésta pueda instituir por propia iniciativa un aniversario para recordar a personas relevantes que han aportado diversos beneficios al monasterio, por lo cual se decide tenerlas en cuenta en las oraciones ${ }^{137}$.

En las inscripciones de Sant Pau se recuerda fundamentalmente a miembros de la comunidad monástica, especialmente a los priores, y a sus familiares. Es el caso de Berenguer de Solicrup (prior), citando en la misma inscripción a su padre, ambos como fundadores de aniversario, de Berenguer de Riu (prior), Guillermo Despuig, Ramón de Olzinelles (prior), en cuya inscripción se recuerda también a su padre Ramón, fundador de otro aniversario, y Pedro Fernández (prior). Si comparamos estos datos con los del priorologio establecido por Pladevall ${ }^{138}$, observamos que desde mediados del siglo XIII hasta los años centrales del XIV todos los priores fundaron aniversarios en Sant Pau. Pedro de Colteller y su mujer Berengaria eran padres de Pedro, monje del monasterio. Ponce era rector de Vila-Rodona y, además de para sí mismo, fundó aniversarios para su madre Blanca Desbosc, su padre y su hermano. Probablemente sea éste el que ofrece el vínculo con Sant Pau, pues tenemos noticias de un monje llamado Ramón Desbosc, que protagoniza un pleito en $1323^{139}$. Asimismo sabemos de otro monje con el mismo apellido, en este caso de nombre Pedro, que llegó a ser ordenado prior y que en marzo de 1319 fue privado de decir misa por un período de cuatro años, por haber accedido al presbiterato de manera fraudulenta en una ceremonia de ordenación general con una edad inferior a la mínima permitida ${ }^{140}$.

${ }^{136}$ Favreau 1995b, p. 256.

${ }^{137}$ Herrero 1994, pp. 225.

${ }^{138}$ Pladevall 1974, p. 33.

${ }^{139}$ Mutgé 2008, pp. 150-151, núm. 35.

${ }^{140}$ Baucells 2004-2007, vol. IV, p. 2952, nn. 111 y 112. 
Supongo personas laicas a aquellas en cuyos epígrafes no se menciona condición alguna, pues ha podido ser comprobado que, al parecer, los monjes citan su estado como tales. Es el caso de Pedro de Pincerna, de los miembros de la familia Gavarreto y de Guillermo de Belloc, descendiente de los fundadores del monasterio y miembro de una familia de importantes benefactores del cenobio, según acredita también el epitaphium sepulcrale de Beltrán de Belloc, en el que se indica qui multa bona huic monasterio contulerunt, refiriéndose a él mismo y a sus antepasados, probablemente Guiberto Guitardo y Rotlendis, artífices de la segunda fundación.

Un caso en cierto modo especial es el de Guillermo de Bruguera. No sabemos exactamente quién fue, ni si perteneció a la comunidad monástica o no. Su inscripción (núm. 3) encierra interrogantes. Es testimonio de la fundación de dos aniversarios concedidos sobre las casas de Ramón de Colpeyeres y Mateo de Coll, Miguel de Coll y Berenguer Vanrell, añadiendo que todo lo que dejó fue comprado a Pedro de Capellades y a Berenguer, su hijo, por precio de tres mil sueldos. Un documento conservado en el Archivo de la Corona de Aragón testimonia la venta de esas propiedades por parte de Pedro de Capellades y Berenguer de Capellades al monasterio de Sant Pau del Camp representado por los monjes Guillermo de Busquetis y Marcho de Portello $^{141}$, con lo que surge la pregunta de, si el monasterio había comprado dichas propiedades, ¿cómo pudo Guillermo de Bruguera fundar un aniversario sobre ellas e indicar que todo lo legado había sido comprado a Pedro de Capellades y a su hijo Berenguer? Hay coincidencia entre el año de la muerte y el de la compra, pues el documento fue dado el 21 de septiembre de 1293. El precio de la compra no es el mismo en la inscripción y en el documento, 3.000 sueldos indica la primera y 97 libras, 9 sólidos y 5 dineros de buena moneda barcelonesa de terno, es decir 1.949,4 sueldos, el segundo. Quizá la explicación está en que las propiedades compradas por el monasterio, indicadas en el documento, fueran financiadas en parte por una donación en metálico legada por Guillermo de Bruguera para asentar el aniversario, según sabemos que se hacía en ocasiones ${ }^{142}$.

Vistos los protagonistas de las inscripciones surge una pregunta para la que, anticipo, no tengo respuesta, ¿por qué justamente estos donatarios fueron honrados con la ejecución de una inscripción y otros fueron relegados al anonimato? Conocemos la existencia de testamentos referentes al monasterio de Sant Pau en los que se establece la fundación de un aniversario, realidad luego no reflejada en ningún epígrafe. Por ejemplo, se conserva el testamento

${ }^{141}$ Mutgé 2002.

${ }^{142}$ Herrero 2011, pp. 214 y 218.

ANUARIO DE Estudios MEDIEVALES, 46/2, julio-diciembre 2016, pp. 939-973 ISSN 0066-5061, doi:10.3989/aem.2016.46.2.11 
de Berenguera Ranca, del 18 de enero de $1225^{143}$, y el de Arsendis de Port, del 26 de enero de $1254^{144}$, personas de las que, sin embargo, no ha quedado memoria epigráfica alguna.

Ya reseñé en el apartado referente a las inscripciones una falta de uniformidad entre la mayor parte de ellas que impide pensar en una autoría común. Esto no permite extender a Sant Pau del Camp lo sucedido en otros centros conocidos como Santo Domingo de Silos, San Juan de la Peña o Roda de Isabena, donde se ha detectado un estilo escriturario y de ejecución similar en la mayor parte de los epígrafes, lo cual ha llevado a pensar en que fueron trazados en un mismo momento, seguramente resultado de la decisión por parte del prior de trasladar a la piedra el libro obituario, conjunto epigráfico que después fue siendo puesto al día por otros artesanos con nuevas defunciones para mantener la actualización del necrologium pétreo ${ }^{145}$. En Sant Pau del Camp, a pesar de que muchas inscripciones contienen datas muy próximas, no existe tal estilo común, lo que lleva a plantear que su autoría física correspondió a lapicidas distintos; tan sólo los epígrafes alusivos a miembros de la familia Belloc, por un lado, y los correspondientes a Berenguer de Solicrup y Berenguer de Riu, por otro, podrían denotar relación en su ejecución. Esta realidad, unida a la finalidad, antes aludida, de garantizar el cumplimiento de las mandas de aniversario, permite formular alguna hipótesis acerca de quién fue el autor moral de las inscripciones.

La diversidad me induce a descartar una autoría por parte del prior del monasterio. Por otro lado la coincidencia de estilo en los epígrafes de los Belloc podría apuntar a que algún miembro de esta familia encargó la realización de estas inscripciones. Esto coincidiría con la finalidad apuntada de garantizar el cumplimiento de las condiciones testamentarias de fundación del aniversario. Tales circunstancias me llevan a plantear la hipótesis de que fueron los propios fundadores de aniversarios, no la comunidad monástica, quienes encargaron la ejecución de las inscripciones, si bien hubieron de contar, lógicamente, con la autorización del prior, quizá como resultado de un acuerdo previo. Realmente eran ellos los más interesados en el cumplimiento de lo estipulado, en que se mantuviera el oficio del aniversario y se prolongara en el tiempo. Al mismo tiempo, sería un modo de mostrar a la comunidad sus obras y donaciones en beneficio de ella. Así pues, al igual que en los obituarios los nombres de los difuntos figuraban por voluntad de éstos, probablemente también la ejecución de las inscripciones obedeciera a su propio deseo. Los protagonistas de los epígrafes quedarían de este modo, y de hecho así ha sido, ligados ad eternum a la comunidad de Sant Pau del Camp.

${ }^{143}$ Mutgé 2002,pp. 103-107, núm. 11.

${ }^{144}$ Ibidem, pp. 134-136, núm. 25.

${ }^{145}$ Durán 1967, pp. 56 y 70. 


\section{BIBLIOGRAFÍA CITADA}

Alföldy, Geza (1991), Augusto e le iscrizioni: tradizione ed innovazione. La nascita dell'epigrafia imperiale, "Scienze dell'Antichità. Storia, Archeologia, Antropologia" 5, pp. 573-600.

Ariès, Philippe (1975), Essais sur l'histoire de la mort en Occident du Moyen Age à nos jours, París, Seuil.

Barroca, Mario Jorge (2000), Epigrafia medieval portuguesa (862-1422), Oporto, Fundaçâo Calouste Gulbenkian.

Baucells, Josep (2004-2007), Vivir en la Edad Media. Barcelona y su entorno en los siglos XIII y XIV (1200-1344), Barcelona, Consejo Superior de Investigaciones Científicas.

Cobos, Antoni; Tremoleda, Joaquim (2009), L'Epigrafia medieval dels comtats gironins. I. El comtat de Peralada, Figueres, Brau.

Cobos, Antoni; Tremoleda, Joaquim; Vega, Salvador (2010), L'Epigrafia medieval dels comtats gironins. II. El comtat d'Empúries, Figueres, Brau.

Debiais, Vincent (2006), Le corpus épigraphique (XIe-XIIIe siècles): les inscriptions dans l'organisation architecturale, en Andrault-Schmitt, Claude (dir.), Saint-Martial de Limoges. Ambition politique et production culturelle (Xe-XIIIe siècles), Limoges, Pulim, pp. 373-390.

Debiais, Vincent (2009), Messages de pierre. La lecture des inscriptions dans la communication médiévale (XIIIe-XIVe siècle), Turnhout, Brepols.

De Rubeis, Flavia (2013), Modelli impaginativi delle iscrizioni funerarie elitarie tra longobardi e carolingi, "Scripta" 6, pp. 57-66.

Di Stefano Manzella, Ivan (1987), Mestiere di epigrafista. Guida a la schedatura del materiale epigrafico lapideo, Roma, Quasar.

Donati, Angela (2002), Epigrafia romana. La comunicazione nell'antichità, Bolonia, Il Mulino.

Durán Gudiol, Antonio (1967), Las inscripciones medievales de la provincia de Huesca, "Estudios de la Edad Media de la Corona de Aragón" 8, pp. 54-153.

Fábrega, Angel (1988), El obituario de la catedral de Barcelona en el siglo XIII, "Anuario de Estudios Medievales" 18, pp. 193-215.

Favreau, Robert (1969), L'épigraphie médiévale, "Cahiers de Civilisation Médiévale" 12, pp. 393-398.

Favreau, Robert (1995a), Functions des inscriptions, en Etudes d'epigraphie medieval, Limoges, Pulim, pp. 155-205.

Favreau, Robert (1995b), Les inscriptions médiévales. Reflet d'une culture et d'une foi, en Etudes d'epigraphie medieval, Limoges, Pulim, pp. 255-314. 
Favreau, Robert; Leplant, Bernadette; Michaud, Jean (1981), Corpus des inscriptions de la France Médiévale. 6. Gers, Landes, Lot-et-Garonne, Pyrénées-atlantiques, París, Éditions du Centre National de la Recherche Scientifique.

Favreau, Robert; Michaud, Jean; Leplant, Bernadette (1982), Corpus des inscriptions de la France Médiévale. 7. Ville de Toulouse, París, Éditions du Centre National de la Recherche Scientifique.

Favreau, Robert; Michaud, Jean; Mora, Bernadette (1986), Corpus des inscriptions de la France Médiévale. 11. Pyrénées-orientales, París, Éditions du Centre National de la Recherche Scientifique.

Favreau, Robert; Michaud, Jean; Mora, Bernadette (1988), Corpus des inscriptions de la France Médiévale. 12. Aude, Hérault, París, Éditions du Centre National de la Recherche Scientifique.

Favreau, Robert; Michaud, Jean; Mora, Bernadette (1990), Corpus des inscriptions de la France Médiévale. 15. La ville de Vienne en Dauphiné, París, Éditions du Centre National de la Recherche Scientifique.

García Lobo, Vicente (1990), La epigrafía del claustro de Silos, en El Románico de Silos. IX centenario de la consagración de la Iglesia y el claustro, Santo Domingo de Silos, Abadía de Silos, pp. 85-104.

García Lobo, Vicente (1991), Los medios de comunicación social en la Edad Media: la comunicación publicitaria, León, Universidad de León.

García Lobo, Vicente (2012), La impaginatio en las inscripciones visigóticas, en Martín López, María Encarnación; García Lobo, Vicente (coords.), Impaginatio en las inscripciones medievales, León, Corpus Inscriptionum Hispaniae Mediaevalium, pp. 9-26.

Garcia Lobo, Vicente; Martín López, María Encarnación (1996), La escritura publicitaria en la Edad Media. Su funcionalidad, "Estudios Humanísticos. Geografía, Historia, Arte" 18, pp. 125-145.

García Morilla, Alejandro (2013), Las inscripciones medievales de la provincia de Burgos: siglos VIII-XIII, Madrid, Universidad Complutense de Madrid.

Gómez-Moreno, Manuel (1953), Discurso de D. Manuel Gómez-Moreno y Martínez, en Navascués y de Juan, Joaquín María, El concepto de la Epigrafía. Consideraciones sobre la necesidad de su ampliación, Madrid, Real Academia de la Historia, pp. 85-102.

Grasby, Richard (1996), A comparative study of five latin inscription measurement and making, "Papers of the British School at Rome" 64, pp. 95-138.

Grasby, Richard (2002), Latin inscriptions: studies in measumrement and making, "Papers of the British School at Rome" 70, pp. 151-176. 
Herrero Jiménez, Mauricio (1994), Colección documental del Archivo de la Catedral de León. Obituarios medievales, León, Caja España de Inversiones - Caja de Ahorros y Monte de Piedad - Archivo Histórico Diocesano de León.

Herrero Jiménez, Mauricio (2011), La muerte en los obituarios medievales, en Galende Díaz, Juan Carlos; Santiago Fernández, Javier de; (dirs.), IX Jornadas Científicas sobre Documentación: la muerte y sus testimonios escritos, Madrid, Universidad Complutense de Madrid, pp. 199-220.

Huyghebaert, Nicolas (1972), Les documents nécrologiques, Turnhout, Brepols.

Koch, Walter (1996), Inscripciones y estudios epigráficos de los países de lengua alemana, "Estudios Humanísticos" 18, pp. 161-182.

Mallon, Jean (1957), Scriptoria épigraphiques, "Scriptorium" 11, pp. 177-194.

Martín López, María Encarnación (2002), El documento como fuente para la Epigrafía, en Morán Suárez, María Antonia; Rodríguez López, María Carmen (eds.), La documentación para la investigación. Homenaje a José Antonio Martín Fuertes, León, Universidad de León, pp. 361-383.

Martín López, María Encarnación (2003), Las inscripciones medievales del monasterio de Santo Domingo de Silos, en Fernández Flórez, José Antonio (dir.), Silos. Un milenio. Actas del Congreso Internacional sobre la Abadía de Santo Domingo de Silos, Burgos, Universidad de Burgos, vol. II, pp. 469-481.

Martín López, María Encarnación (2010), Las inscripciones diplomáticas en el período gótico, en Martín López, María Encarnación; García Lobo, Vicente (eds.), Las inscripciones góticas, León, Corpus Inscriptionum Hispaniae Mediaevalium, pp. 97-123.

Martín López, María Encarnación (2012), Impaginatio, en Martín López, María Encarnación; García Lobo, Vicente (coords.), Impaginatio en las inscripciones medievales, León, Corpus Inscriptionum Hispaniae Mediaevalium, pp. 231-246.

Martín López, María Encarnación; García Lobo, Vicente (2009), La Epigrafía Medieval en España. Por una tipología de las inscripciones, en Galende Díaz, Juan Carlos; Santiago Fernández, Javier de; (dirs.), VIII Jornadas Científicas sobre documentación de la Hispania altomedieval (siglos VI-X), Madrid, Universidad Complutense de Madrid, pp. 185-213.

Martín López, María Encarnación; García Lobo, Vicente (coords.) (2012), Impaginatio en las inscripciones medievales, León, Corpus Inscriptionum Hispaniae Mediaevalium. 
Mas, Joseph (1911), Notes históriques del Bisbat de Barcelona, vol. VIII, Lo fosar de la Sèu de Barcelona y ses inscripcions funeraries, Barcelona, Establiment Tipográfich de Eugeni Subirana.

Mutgé, Josefina (1992-1993), Noticies historiques sobre el monestir de Sant Pau del Camp, "Anales de la Universidad de Alicante. Historia Medieval" 9, pp. 101-118.

Mutgé, Josefina (2002), Pergamins del monestir benedictí de Sant Pau del Camp de Barcelona de l'Arxiu de la Corona d'Aragó (segles XII$X I V)$, Barcelona, Consejo Superior de Investigaciones Científicas. Institución Milà i Fontanals.

Mutgé, Josefina (2008), El monestir benedictí de Sant Pau del Camp de Barcelona a través de la documentació de cancelleria reial de l'Arxiu de la Corona de Aragó (1287-1510), Barcelona, Fundació Noguera.

Nonó, Brígida (2003), Aquí es redacten i s'esculpeixen inscripcions. Aproximació al corpus epigràfic de la ciutat de Girona, Girona, Universitat de Girona.

Orlandis, José (1976), La elección de sepultura en la España Medieval, en Idem, La Iglesia en la España visigótica y medieval, Pamplona, Eunsa, pp. 257-306.

Petrucci, Armando (1986), La scrittura: ideologia e rappresentazione, Turín, G. Einaudi.

Pladevall, Antoni (1974), La història, en Vigué, Jordi, El monestir romànic de Sant Pau del Camp, Barcelona, Artestudi, pp. 17-64.

Pujades, Gerónimo (1830), Crónica Universal de Cataluña, $2^{\text {a }}$ parte, libro 9 , Barcelona.

Robert, Louis (1961), Épigrahie, en Samaran, Charles (coord.), L'histoire et ses méthodes. Encyclopédie de la Pléiade, París, Gallimard, pp. 453-497.

Rodríguez Suárez, Natalia (2009), Fórmulas diplomáticas en las inscripciones medievales redactadas en romance, "Espacio, Tiempo y Forma. Serie III, Historia Medieval" 22, pp. 301-329.

Santiago, Javier de (2003), La epigrafía latina medieval en los condados catalanes (815-c. 1150), Madrid, A.C. Castellum.

Sartori, Antonio (1995), L'impaginazione delle iscrizioni, "Commentationes Humanarum Litterarum" 104, pp. 183-200.

Sartori, Antonio (1996), La composizione delle epigrafi latine: un'accorta tecnica spontanea, en Khanoussi, Mustapha; Ruggeri, Paola; Vismara, Cinzia (eds.), L'Africa Romana: atti del XI convegno di studio, Ozieri, Editrice Il Torchietto, pp. 215-222.

Serna, Sonia (2008), Los obituarios de la catedral de Burgos, León, Centro de Estudios e Investigación San Isidoro. 
Susini, Giancarlo (1968), Il lapicida romano. Introduzione all'epigrafia lati$n a$, Roma, L'Erma di Bretschneider.

Susini, Giancarlo (1989), Le scritture esposte, en Lo spazio letterario di Roma antica. 2. La circolazione del testo, Roma, Salerno, pp. 271-305.

Treffort, Cécile (2008), De l'inscription nécrologique à l'obituaire lapidaire: la mémoire comme signe d'appartenance à la communauté, en Tristano, Caterina; Allegria, Simone (eds.), Civis / Civitas. Cittadinanza politico-istituzionale e identità socio-culturale da Roma alla prima età moderna, Montepulciano, Thesan \& Turan, pp. 117-140.

Treffort, Cécile (2010), Les inscriptions funéraires des XIIe et XIIIe siècles en France, en Martín López, $\mathrm{M}^{\mathrm{a}}$ Encarnación; García Lobo, Vicente (eds.), Las inscripciones góticas, León, Corpus Inscriptionum Hispaniae Mediaevalium, pp. 161-184.

Vigué, Jordi (1974), El monestir romànic de Sant Pau del Camp, Barcelona, Artestudi.

Fecha de recepción del artículo: septiembre 2013

Fecha de aceptacióny versión final: julio 2014 